\title{
Access to scientific literature by the conservation community
}

\author{
Daisy Larios $^{\text {Corresp., } 1}$, Thomas M Brooks ${ }^{1}$, Nicholas BW Macfarlane ${ }^{2}$, Sugoto Roy $^{3}$ \\ 1 Science and Knowledge Unit, International Union for Conservation of Nature (IUCN), Gland, Vaud, Switzerland \\ 2 Science and Knowledge Unit, International Union for Conservation of Nature (IUCN), Washington D.C., United States of America \\ ${ }^{3}$ Global Species \& Key Biodiversity Areas Programme, International Union for Conservation of Nature (IUCN), Gland, Vaud, Switzerland \\ Corresponding Author: Daisy Larios \\ Email address: daisy.larios@iucn.org
}

Access to the scientific literature is perceived to be a challenge to the biodiversity conservation community, but actual level of literature access relative to needs has never been assessed globally. We examined this question by surveying the constituency of the International Union for Conservation of Nature (IUCN) as a proxy for the conservation community, generating 2,285 responses. Of these respondents, $\sim 97 \%$ need to use the scientific literature in order to support their IUCN-related conservation work, with $\sim 50 \%$ needing to do so at least once per week. The crux of the survey revolved around the question, "How easy is it for you currently to obtain the scientific literature you need to carry out your IUCN-related work?" and revealed that roughly half (49\%) of the respondents find it not easy or not at all easy to access scientific literature. We fitted a binary logistic regression model to explore factors predicting ease of literature access. Whether the respondent had institutional literature access $(55 \%$ do) is the strongest predictor, with region (Western Europe, the United States, Canada, Australia and New Zealand) and gender (male) also significant predictors. Approximately $60 \%$ of respondents from Western Europe, the United States, Canada, Australia and New Zealand have institutional access compared to $\sim 50 \%$ in Asia and Latin America, and $\sim 40 \%$ in Eastern Europe and in Africa. Nevertheless, accessing free online material is a popular means of accessing literature for both those with and without institutional access. The four journals most frequently mentioned when asked which journal access would deliver the greatest improvements to the respondent's IUCN-related work were Conservation Biology, Biological Conservation, Nature, and Science. The majority prefer to read journal articles on screen but prefer to read books in hard copy. Overall, it is apparent that access to the literature is a challenge facing roughly half of the conservation community worldwide. 
1 Access to Scientific Literature by the Conservation

2 Community

$3{\text { Daisy } \operatorname{Larios}^{1} \text {, Thomas M. Brooks }}^{1}$, Nicholas B.W. Macfarlane ${ }^{2}$, Sugoto Roy ${ }^{3}$

$4{ }^{1}$ Science and Knowledge Unit, International Union for Conservation of Nature (IUCN), Gland, Vaud, Switzerland

$5 \quad{ }^{2}$ Science and Knowledge Unit, International Union for Conservation of Nature (IUCN), Washington D.C., United

6 States of America

$7 \quad{ }^{3}$ Global Species \& Key Biodiversity Areas Programme, International Union for Conservation of Nature (IUCN),

8 Gland, Vaud, Switzerland

9 Corresponding Author:

10 Daisy Larios ${ }^{1}$

11 Email address: daisy.larios@iucn.org

12

13

14

15

16

17

18

19

20

21

22

23

24

25

26

27

28

29

30

31

32

33

34

Abstract

Access to the scientific literature is perceived to be a challenge to the biodiversity conservation community, but actual level of literature access relative to needs has never been assessed globally. We examined this question by surveying the constituency of the International Union for Conservation of Nature (IUCN) as a proxy for the conservation community, generating 2,285 responses. Of these respondents, $\sim 97 \%$ need to use the scientific literature in order to support their IUCN-related conservation work, with $\sim 50 \%$ needing to do so at least once per week. The crux of the survey revolved around the question, "How easy is it for you currently to obtain the scientific literature you need to carry out your IUCN-related work?" and revealed that roughly half $(49 \%)$ of the respondents find it not easy or not at all easy to access scientific literature. We fitted a binary logistic regression model to explore factors predicting ease of literature access. Whether the respondent had institutional literature access $(55 \%$ do $)$ is the strongest predictor, with region (Western Europe, the United States, Canada, Australia and New Zealand) and gender (male) also significant predictors. Approximately $60 \%$ of respondents from Western Europe, the United States, Canada, Australia and New Zealand have institutional access compared to $\sim 50 \%$ in Asia and Latin America, and $\sim 40 \%$ in Eastern Europe and in Africa. Nevertheless, accessing free online material is a popular means of accessing literature for both those with and without institutional access. The four journals most frequently mentioned when asked which journal access would deliver the greatest improvements to the respondent's IUCN-related work were Conservation Biology, Biological Conservation, Nature, and Science. The majority prefer to read journal articles on screen but prefer to read books in hard copy. Overall, it is apparent that access to the literature is a challenge facing roughly half of the conservation community worldwide. 
Introduction

A commonly held belief through the conservation community is that lack of access to the scientific literature is a limiting factor for practitioners (Fonseca \& Benson, 2003; Rafidimanantsoa et al, 2018; Amano et al., 2016). This assumption stands to reason given the evidence that access to information would improve conservation outcomes (Cook et al., 2010; Walsh et al., 2015) as well as the documentation of shortfalls in literature access from other fields of applied science (Horton, 2000, Godlee et al., 2004). This creates a challenge for conservation, especially given that there appears to be an inverse relationship between where research takes place and where it is most needed (Rodrigues et al., 2010; Wilson et al., 2016). Meanwhile, library science literature has generally focused its studies on the information needs and behaviours of scientists and scholars, only more recently expanding its scope to consider the needs of nonacademic professionals (Leckie et al., 1996). For conservation, previous studies have found that those in sectors other than academia and government experience the most difficulty in finding the biodiversity information they need to do their work (Steiner Davis et al., 2014; Fabian et al., 2019). Despite some evidence that scientific journals do not contain the type of information considered most important by conservation professionals (Roy, Smith \& Russell, 2009; Fabian et al., 2019), the degree to which access to the scientific literature meets the stated needs of the global community has never been assessed, and little consideration has been given to the role of libraries in facilitating access to literature.

Existing models of information seeking tend to focus on specific professionals or academic groups, but biodiversity conservation is undertaken by a web of actors that goes beyond scientists and academics to include on-the-ground practitioners as well as employees of NGOs and governments. We therefore surveyed the constituency of the International Union for the Conservation of Nature (IUCN) to determine the extent of literature access from among the world's conservation professionals and to which their institution facilitates access to literature.

Created in 1948, IUCN is a Membership Union uniquely composed of both governments and state agencies (223 in total) and civil society and indigenous peoples' organisations (1,117 in total), with each of these two houses having equal weight in the Union's governance. Members approve the mandates of expert Commissions, of which there are currently six, encompassing some 13,000 experts who lend their expertise to IUCN. The Members also elect a Council that appoints a Director-General, who in turn recruits a professional Secretariat, comprising roughly 1,000 employees. Given this breadth of IUCN's makeup, respondents to our survey could have a variety of backgrounds and roles: from environmental practitioners, nonprofit workers, and governmental decision makers to academics and consultants. Here, we refer to this complex group of survey respondents as "conservation professionals" for simplicity's sake. Nonetheless, it could include respondents who work within environmental organizations in financial, administrative, or legal capacities (i.e. employees of IUCN Members or the IUCN Secretariat) 
78

and exclude conservation professionals who are not IUCN Commission members and if they work for organizations whose focus is not conservation (e.g. watershed councils and city governments) or that otherwise are not Members of IUCN.

IUCN has always served a role in supporting access to conservation knowledge and literature, a role historically held to be critical to supporting the goals of conservation. When it was founded in Fontainebleau on 5 October 1948 as the International Union for the Protection of Nature (IUPN), one of its original objectives was to "collect, analyse, interpret and disseminate information about the "Protection of Nature"" (Büttikofer, 1946). It regarded the International Office for the Protection of Nature, one of its founding international organisational members, as essential in carrying out this objective (IUCN, 1951). The Office's predecessor, the Central Bureau of Information and Correlation, was founded at the 1928 General Assembly of the International Union of Biological Sciences by the National Committees of Belgium, France and Holland, who saw the Bureau as an important step towards the ultimate goal of creating an international union (Büttikofer, 1947). Organisations dedicated to the protection of nature were to send publications to the Bureau to facilitate the later establishment of this international union (Büttikofer, 1946). The Bureau was replaced by the International Office for the Protection of Nature in December 1935 and transferred to Amsterdam in 1940 at the outbreak of World War II, which severely limited the Office's finances. By 1947, though, it had been modestly reestablished as a "scientific institution, a library, a record-office, a centre for receiving, classifying and publishing data, for organizing inquiries, for propaganda and information" (Büttikofer, 1947). The Office finally merged with IUPN in 1955, taking the name of the Office's founder: Bibliothèque van Tienhoven. The IUCN HQ Library over the years has built upon the original collection inherited from the Office.

We intend for the results of this survey to have immediate practical implications. Most directly, our results will steer the strategy for IUCN and other conservation organisations in strengthening their institutional commitment to their own libraries. Second, they should also provide useful insight for conservation libraries housed throughout the IUCN Membership. Equally, actors in the complex publishing landscape of conservation research - involving commercial publishers, non-profit publishers, universities, academics and conservation organisations under a number of arrangements - may be able to draw from our findings to enhance their readerships and impact. Finally, our results may be valuable to foundations and other funding agencies that support conservation, in seeking to optimise their investments.

\section{Materials and Methods}

The survey consisted of fifteen questions divided over four pages (Supplementary Online Material). References to "scientific literature" throughout the survey were defined as "peer- 
114 reviewed scientific journals plus technical books" in the introductory text to the survey. We

115

116

117

118

119

120

121

122

123

124

125

126

127

128

129

130

131

132

133

134

135

136

137

138

139

140

141

142

143

144

145

146

147

148

149

150

151

152

153 define "institutional access to scientific literature online" to mean that the respondent's employer or some other institution to which they have an affiliation (e.g. a university) has a library or library-like department that negotiates online subscriptions to journals or databases on behalf of the institution's users. We did not use the word "library" because users may strictly associate libraries with a physical space, unaware that access to journals or databases (often seamlessly authorized by IP address) is facilitated by the institution's library (Tenopir, Christian \& Kaufman, 2019). A library does not necessarily have to be in a physical space, as can be seen in the definition proposed by the American Library Association: "A library is a collection of resources in a variety of formats that is 1 ) organized by information professionals or other experts who 2) provide convenient physical, digital, bibliographic, or intellectual access and 3) offer targeted services and programs 4) with the mission of educating, informing, or entertaining a variety of audiences 5) and the goal of stimulating individual learning and advancing society as a whole" (American Library Association). We made reference throughout the survey to access to scientific literature for the purposes of "IUCN-related work", given the scope of the IUCN HQ Library.

The survey's first page collected demographic information about the respondent, with a fourth question asking how frequently the respondent perceived that they should be consulting scientific literature to carry out their IUCN-related work. We utilized the word "should" to distinguish between actual and required use of literature, since actual use could be suppressed due to lack of access. Results for the remaining questions only include those of respondents who required scientific literature in the course of their IUCN-related work; those who answered "Never" to this question were taken to the final page of the survey. The second page used multiple-choice questions to determine the ease and importance of the respondent's access to the literature; asked which one journal would have the largest impact on the respondent's work were they to have access; and explored preferred reading formats, whether the respondent has institutional access to the literature, and frequency of different methods of literature access. The survey logic was designed so that those who reported no institutional access were taken to a third page, which asked respondents to assess likely frequency and impact of use were they to have such access. The final page offered respondents the opportunity to leave comments and contact details.

The survey was made available in all three official IUCN languages (Spanish, French, English) via two separate emails on 19 July 2016 to (i) primary contacts for all IUCN Member organizations, who were asked to forward the message to those individuals undertaking IUCNrelated work within their institution, (ii) all IUCN Secretariat staff, and (iii) all members of the six IUCN Commissions for 2013-2016. These categories are non-exclusive: an individual could be a member of more than one Commission, or could simultaneously be a Commission member and an employee of a Member organization or of the IUCN Secretariat. Membership sizes of the Commissions vary, with most having $\sim 1,000$ members and the Species Survival Commission

Peer) reviewing PDF | (2019:11:43492:2:1:NEW 18 May 2020) 
154 having $\sim 10,000$ members. The language in which the survey was sent was determined by

155

156

157

158

159

160

161

162

163

164

165

166

167

168

169

170

171

172

173

174

175

176

177

178

179

180

181

182

183

184

185

186

187

188

189

190

191

192

whether the contact had an indicated language of preference in IUCN's customer relationship management (CRM) system; those without a preference received the English-language version by default. We sought to be inclusive of all who had any need for scientific literature in their IUCN-related work and did not seek to limit the survey to those of particular roles or backgrounds. Therefore, our survey results likely include some responses from individuals who work in areas other than biodiversity conservation and require other types of literature e.g. legal or management literature. We sent a reminder on 10 August 2016 and the survey was closed on 12 August 2016. The survey was wholly voluntary.

We aggregated results by country according to the UN regional groups-Africa, Asia-Pacific, Eastern Europe, Latin America and the Caribbean, and Western Europe and Others (which includes the United States, Canada, Australia and New Zealand). While a range of other national socio-economic parameters (e.g. GDP, income equality, education of girls and boys) could be included, we chose to select these regional groupings to reflect political and social as well as economic similarities in as small a number of groups as possible, in a way informative for decision-making in conservation, libraries, and other relevant institutions.

To compare the relationship between a respondent's answers to the demographic and professional questions on their perception of ease of access to necessary literature, we modeled ease of access by condensing responses to the ease of access question into a binary variable (very hard + hard $=0$, easy + very easy $=1$ ) and fitting a binary logistic regression model to the full rank dataset of 1,970 respondents who answered all questions under consideration in the model. We began with consideration of five variables suspected likely to influence ease of literature access: institutional access [yes/no], institutional affiliation [five categories], discipline as reflected by Commission membership [six non-exclusive categories], gender [two categories], and region [five categories]. Language was not included as a factor given the relatively low number of responses in Spanish and French compared to English; however, responses from all three language variations of the survey were included in the model. Standard variable selection approaches based on AIC scores (Akaike, 1974), resulted in a final model of the probability of access being easy as a function of Region (as compared to a base case region of Africa), Gender ("male" compared to "female"), and Institutional Access ("yes" compared to "no") (Table 1). The base case of Africa, female, and no institutional access was chosen for comparison because those respondents reported the most difficult access. Institutional affiliation and Commission membership did not emerge as significant predictors in the model. In addition, interactions were explored between gender and region, and gender and institutional access, neither of which were significant. There was some evidence for an interaction between institutional access and being in the Western Europe and Others Group, which did not change the overall conclusions and was not included given the principles of parsimony and statistical efficiency, and the complexities of

Peer) reviewing PDF | (2019:11:43492:2:1:NEW 18 May 2020) 
193 interpreting interaction terms in non-linear models (Ai \& Norton, 2003). All model fitting was 194 conducted using R (R Development Core team, 2017)

197

198

199

200

201

202

203

204

205

206

207

208

209

210

211

212

213

214

215

216

217

218

219

220

221

222

223

224

225

226

227

228

229

In total, we received 2,285 responses to our survey, though not all respondents answered all questions. This represents $13 \%$ of the IUCN constituency to whom the survey was directly distributed, although it is difficult to give a precise return rate given that there would have been some overlap between contact lists and as the actual number of potential participants among IUCN Members is unknown (Table 1). Anecdotal email responses suggest that some Member focal points erroneously thought the survey should be filled out on behalf of the entire organization. Also, our results will be biased against those who did not have internet access during the time of survey (who are in turn likely to have poor access to the scientific literature in the first place). Nearly all (87\%) responses were to the English-language version, and the vast majority (97\%) of respondents felt they should be accessing scientific literature at least once per month (Figure 1).

\section{How easily can the conservation community access scientific literature?}

The survey revolved around the question, "How easy is it for you currently to obtain the scientific literature you need to carry out your IUCN-related work?" Roughly half $(49 \%)$ of all 2,004 respondents to this question find it not easy or not at all easy to access scientific literature (Figure 2).

Overall, $47 \%$ of the 2,004 respondents to the question reported having no institutional access to scientific literature online, which correlates greatly to ease of access to literature. Among those with online institutional access, $72 \%$ found it easy to obtain access to required literature. By contrast, a similar percentage (74\%) of those reporting no institutional access found it difficult to access scientific literature (Figure 3).

Not surprisingly, then, institutional access was the primary explanatory variable predicting ease of access. Exponentiating the model coefficient shows that institutional access increased the odds of easy access to literature by a factor of 6.86; it would seem that affiliation with an institution with a library greatly increases the odds of easy access to scientific literature. Being male and being based in the Western Europe and Others Group were also significant predictors of ease of access (Table 2). 
230 Respondents to our survey were based in 170 countries, allowing us to examine variation across

231

232

233

234

235

236

237

238

239

240

241

242

243

244

245

246

247

248

249

250

251

252

253

254

255

256

257

258

259

260

261

262

263

264

265

266

267

268

269 the five United Nations regional socio-geographical groupings. Nearly half of respondents belonged to the Western Europe and Others Group (Figure 4). The two socio-geographic areas with the greatest difficulty in obtaining scientific literature were Africa and Eastern Europe, with $63 \%$ of respondents from Africa and $57 \%$ of respondents from Eastern Europe reporting that accessing scientific literature as not easy or not at all easy (Figure 5). Not surprisingly, these two regions also reported the least online institutional access to scientific literature (Figure 6). This supports our model findings that being based in a country in the Western Europe and Others group as opposed to one in Africa increased the odds of easy access by a factor of 1.73 , as shown by exponentiating the region coefficient (Table 2). Other regions were not significant predictors. A Tukey's post hoc test showed regional differences between Africa and Western Europe and Others $(p=0.005)$, but no significant differences between all other pairwise combinations of regions (Table 3$)$.

More than twice as many men (1,556 respondents) as women (710 respondents) took the survey. Of the 604 female respondents to the question about institutional access, 52\% reported having institutional access, compared to $54 \%$ of the 1,387 male respondents to this question. When all other factors were held constant, our final model predicts that men have higher odds of easy access than women, at an odds ratio of 1.38 (Table 2). Interactions between gender, region, and institutional access were not significant, so there is not strong evidence for co-variation between gender and other variables in the model. However, the number of male and female respondents could potentially impact the interpretation of the gender effect if they don't appropriately reflect the population.

Overall, 1,738 of our survey respondents reported being a member of one (or more) of IUCN's six expert Commissions. By taking Commission membership as a proxy for discipline specialisation, we examined variation across thematic issues in conservation. (This approach excludes the 547 respondents who do not belong to any Commission). Numbers of responses mirrored the size of each of the six Commissions. Overall, membership in a particular Commission did not emerge as a significant predictor of ease of access in our model. Institutional access to the scientific literature did vary though, from $60 \%$ among those whose specialisation includes environmental law to $42 \%$ among those whose expertise includes protected areas (Table 4).

Overall, 656 of all survey respondents reported being an employee of IUCN itself or an IUCN Member organization, which we used to assess variation by sector. However, as respondents as a whole were not specifically asked to identify their work sector or employer, this partial snapshot excludes the work sectors of the 1,524 respondents who identified solely as Commission members. Sector categories are non-mutually exclusive, as 34 respondents selected more than one Membership category (presumably these are individuals who have multiple institutional

Peer) reviewing PDF | (2019:11:43492:2:1:NEW 18 May 2020) 
270 affiliations). Here we consider responses from the IUCN Secretariat as well as four of IUCN's

271 Membership categories, combining responses from staff of States and of Government agencies.

272 We do not consider Affiliates - because this non-voting category combines governments and

273 NGOs - or Indigenous Peoples' Organisations, because this category was established subsequent

274 to completion of our data collection in September 2016 (WCC-2016-Res-004).

275

276 While institutional affiliation did not emerge as a predictor of access, nevertheless there were

277 differences in levels of institutional access to scientific literature. Among these sectoral groups,

278 individuals working for states and/or government agencies reported having the best institutional

279 access (Table 5). The lowest levels of access by far are among the IUCN Secretariat, with only $28028 \%$ of the staff reporting institutional access (the IUCN Library does not have an acquisitions 281 budget). It may be that government agencies and entities are more likely than NGOs to have 282 libraries and/or librarians to support the information needs of government workers.

283

284 285

286

287

288

289

290

291

292

293

294

295

296

297

298

299

300

301

302

303

304

305

306

307

How important is access to scientific literature for the conservation community?

Most respondents to our survey (regardless of institutional access) felt that easy access to scientific literature was either essential or very important to their work with IUCN (Figure 7). This supports other findings that peer-reviewed publications remain important among science researchers generally as well as among restoration practitioners and public and private land managers (Seavy \& Howell, 2010; Tenopir, Christian \& Kaufman, 2019).

Of the 1,458 respondents who felt it was either very important or essential to have easy access to scientific literature, $39 \%$ reported that they should be consulting scientific literature either sometimes (once a month) (29\%) or infrequently (10\%). Thus, there is a sizeable proportion of conservation professionals who do not need to access scientific literature on a frequent basis but for whom it is still very important to do so at least occasionally. For libraries with limited budgets, this could suggest that a pay-per-use model might be preferable to journal or database subscription models.

We sought to quantify the importance of online institutional access to scientific literature further by asking additional questions of those respondents who stated they did not have institutional access to scientific literature online. The majority of these respondents reported that the lack of institutional access to scientific literature online has a moderate to great negative impact on their IUCN-related work (Figure 8). The narrative comments on this question reveal another concern beyond the negative impact on the quality of the work: time wasted trying to find appropriate literature. For example: 
308

309

310

311

312

313

314

315

316

317

318

319

320

321

322

323

324

325

326

327

328

329

330

331

332

333

334

335

336

337

338

339

340

341

342

343

344

345
- "I waste time searching for free versions of papers online. I waste time getting frustrated that I can't find free versions for everything I need. I cut corners scientifically which I don't like. I am not up to date professionally. I am not able to adequately pursue my own professional development."

- "Time spent chasing articles from colleagues could be better spent using findings."

The impacts of lack of access are perceived as more severe in some regions than in others.

Notably, 29\% of respondents from Africa reported their lack of institutional access as incurring a great negative impact; in Latin America and the Caribbean it was $24 \%$ and in all other regions $<20 \%$. Other variation was minimal: among sectors, lack of access is felt most keenly among those working for national NGOs (20\% reporting great negative impact), while among disciplines it is felt most strongly by specialists in law (22\%), ecosystems, and education and communication (both $21 \%$ ). Among all respondents, the rate was $16 \%$. These results can guide the efforts of funders seeking to make the greatest gains in improving access to literature for impact: for example, they suggest increased funding for conservation libraries would make particular impact within national environmental NGOs.

Most respondents reported that obtaining institutional access would have a moderate to great positive effect on the quality of their IUCN-related work (Figure 9). Narrative comments suggest that a range of benefits would be accrued from library-facilitated access to literature online, including strengthening innovation, efficiency, and credibility:

- "Work would be more thorough, more inclusive, more efficient."

- "No effect on quality, but direct access would speed up my work at times."

- "It will allow me to produce better Red List assessments as well as other types of reports."

More than three-fifths of respondents without institutional access anticipate that they would access the literature frequently or very frequently if they did have access (Figure 10) - ten percent higher than the $51 \%$ of all 2,285 respondents who felt that they should be accessing the literature frequently or very frequently. Thus we might expect that providing library-facilitated online access to scientific literature would allow those in the conservation community to access and use literature more frequently.

\section{Information pathways and preferences}

We asked respondents to identify how frequently they used various means to access scientific literature; their answers shed light on the preferred (or available) pathways, both formal and 
346 informal, to scientific literature for those with and without institutional access to literature

347 (Figure 11).

348

349 Unsurprisingly, respondents with institutional access to scientific literature reported using the

350 library of their own institution and institutional access to literature online more frequently than

351 those without; meanwhile, those without institutional access reported asking friends or

352 colleagues with access to literature and using free online resources (such as Google Scholar or

353 ResearchGate) more frequently. However, accessing free online material is a popular means of

354 accessing literature for both groups. These findings are expected, given the critical role of access

355 in influencing information-seeking behaviour (Connaway et al., 2011) and the prevalence and

356 necessity of informal and alternative routes of access in countries with poor access to literature,

357 such as India (Gaulé, 2009; Boudry et al, 2019). It also reflects a previous study that found open-

358 access literature to be the most important source of information among conservation practitioners

359 as well as university and non-university researchers in low-middle income countries (Gossa et

360 al., 2015). Although our survey did not attempt to specifically address the impact of websites

361 such as Sci-Hub and LibGen that enable users to download PDFs of scholarly articles, the

362 popularity of accessing "whatever I can find online for free" among those without and with

363 institutional access implies that such mechanisms are popular even among academic researchers

364 (Greshake, 2016; Bohannon, 2016). Indeed, our survey might even be underreporting the

365 popularity of accessing free papers online, given that some researchers might be prohibited from

366 (by their institution's firewalls) or uncomfortable with using certain sites due to their illegal

367 nature. Nevertheless, with freely available papers obtaining $18 \%$ more citations than expected

368 (Piwowar et al., 2018), this method of accessing literature is becoming increasingly important.

369

370

We also asked respondents about their preferred means of reading scientific literature as well as

371

372

which one journal would have the largest impact on their IUCN-related work if they could obtain access to it. Together, these questions were designed to help guide strategic decision-making for

373 conservation libraries.

374

375 Of the 2,116 respondents to the English and French surveys, 1,238 (59\%) provided answers to

376 the question "Which one scientific journal would have the largest impact on your IUCN-related

377 work if you could obtain easy access to it?" (this question was accidentally omitted from the

378 Spanish survey). Of these, 794 listed specific journal names, which were classified and tallied to

379 identify those journals to which conservationists perceive that access would benefit their work

380 most greatly. Some respondents listed more than one journal: in such cases, scores were divided

381

382

383 In total, 235 journals were mentioned by respondents, including ten listed as most desired more 384 than ten times. These included six specialist conservation journals (Conservation Biology,

385 Biological Conservation, Oryx, Journal of Wildlife Management, Biodiversity \& Conservation, 
386

387

388

389

390

391

392

393

394

395

396

397

398

399

400

401

402

403

404

405

406

407

408

409

410

411

412

413

414

415

416

417

418

419

420

421

422

423

424

and Parks), two general science journals (Nature and Science), one general ecological journal (Ecology), and one general taxonomic journal (Zootaxa) (Table 6). There is no significant relationship between the number of times that specific journals were mentioned by respondents as those to which they most desired access and the 2015 Google Scholar h5 index value of these journals (Figure 12). This mirrors results of weak or no relationships between popularity of journals with practitioners and their journal impact factors from conservation (Gossa et al., 2015) and other fields, such as surgery (Jones et al., 2006). Nevertheless, the variety of responses demonstrates the diversity of conservation community's scientific literature needs, which suggests that a pay-per-view or pay-per-article model might be more cost-effective for smaller libraries than traditional journal title or database subscriptions.

In addition to preferred journals, conservation professionals also have different preferred reading formats between books and journal articles. To discern this difference, we asked in Question 8, "In what format do you prefer to read scientific literature?" where the choices were "I prefer reading on a screen", "I prefer printing out to read," and "I prefer the original hard copy." When reading articles from scientific journals, the majority (59\%) prefer reading on screen, but for books, the majority (59\%) prefer to read the original hard copy. The preference for electronic journals has been noted elsewhere (Kaur, 2012).

\section{Discussion}

Our most striking findings are two-fold. First, despite the fact that $97 \%$ of respondents need it for their IUCN-related work, approximately half of the conservation community we surveyed report not having easy access to scientific literature. This stark division in ease of access to scientific literature confirms earlier findings on the difficulties of accessing literature (Cvitanoic et al., 2014; Steiner Davis et al., 2014). Second, gender, region, and, in particular, institutional access, had statistically significant effects on ease of access to scientific literature. Considering that SciHub, for example, provides greater coverage than the University of Pennsylvania to "toll access" journal articles (Himmelstein, 2017), the persistent relevance of institutional access was surprising but nonetheless points to the need for continued support of institutional libraries.

Much concern has been raised about the challenges to the scientific process faced by Africa, Asia-Pacific, and Latin America and the Caribbean (Barber et al., 2014, Pasgaard \& Strange, 2013). This geographical variation in where conservation science is produced and published is potentially related to the geographical variation in access to the literature (Karlsson et al., 2007; Fisher, 2015; Gossa et al., 2015; Nuñez et al., 2019). An information gap as well as "digital divide" (Coloma \& Harris, 2005) between lower and higher income countries has long been acknowledged, and our results confirm that the conservation community in high-income countries have greater easy access than their counterparts in the rest of the world. However, even in middle-high income countries, over $40 \%$ of our respondents report not having easy access to 
425

426

427

428

429

430

431

432

433

434

435

436

437

438

439

440

441

442

443

444

445

446

447

448

449

450

451

452

453

454

455

456

457

458

459

460

461

462

463

464

scientific literature online. Additionally, Eastern Europe, which had the second greatest difficulty in access to the literature, is rarely highlighted in assessments of the topic. Our finding that this information gap divides gender as well as geography is presumably both a symptom and a cause of the underrepresentation of women in science (Ceci \& Williams, 2011).

One approach to addressing the issue of access has been the number of worldwide programs and initiatives designed to expand scientific access to lower income countries, such as Research4Life (Burton, 2011; Bartol et al., 2013; http://www.research4life.org), in which institutions in eligible countries may register for free or discounted access to scientific journals. Various individual publishers, such as the University of Chicago Press (http://www.journals.uchicago.edu/inst/ceni) and Oxford University Press (http://www.oxfordjournals.org/en/librarians/developing-countriesinitiative/), offer similar programs. However, there are limitations to such systems (Smith et al., 2007; Chan et al., 2011; Villafuerte-Gálvez, Curioso \& Gayoso, 2007; Bendezú-Quispe et al., 2016). The factors taken into consideration to determine whether a country is eligible for Research4Life include total gross national income and the country's Human Development Index, among others, but the combination of these factors means that no countries in Eastern Europe qualify for free access under Research4Life even though Eastern European respondents to our survey reported the second-lowest rates of institutional access to conservation literature (after Africa). Furthermore, several countries that would qualify for discounts according to World Bank criteria are not on the list (Chan et al., 2012). Additionally, programmes such as Research4Life do not consider that even within high income countries, access to literature is not universal (Chan et al., 2012). Finally, the Research4Life registration requires the contact information of the organization's Librarian or Information Specialist. However, roughly half of our survey respondents, no matter where in the world they were located, report having no institutional access to scientific literature online, which suggests the lack of an institutional library to begin with, or at best a severely underfunded one.

Although the conservation literature recognizes the research-implementation gap and even calls for investment in "knowledge brokers" (Cvitanovic et al., 2014; Sheikheldin et al., 2010), it rarely acknowledges the role of libraries in improving information flow, despite the fact that access to literature is traditionally brokered by an organization's library. Having institutional access to literature online increases the odds of easier access to literature by nearly seven times, which suggests that core support of libraries within institutions is key to improving access. The impact of the lack of institutional access is felt not just in the quality of work being produced, but also in loss of credibility and the amount of time required to obtain papers. One study found a correlation between e-journal consumption and research outcomes (Research Information Network, 2009), suggesting that the access provided by a well-funded library could have positive impacts beyond simply saving time. Calls for evidence-based approaches in conservation that prioritize the use of synthesized knowledge such as systematic reviews over traditional journal articles, akin to those employed in medicine and public health (Pullin \& Knight, 2003; Cullen et 
465 al., 2001) stop short of acknowledging the crucial role of librarians in medical systematic

466

467

468

469

470

471

472

473

474

475

476

477

478

479

480

481

482

483

484

485

486

487

488

489

490

491

492

493

494

495

496

497

498

499

500

501

502

503

504

reviews (Harris, 2005). Even the sharing of lessons learned from field projects is impeded by the lack of institutional support to library and information management; most conservation projects fail to document their work internally, and project libraries are not well-managed (Sayer \& Campbell, 2004). This suggests that donors as well as conservation institutions themselves have a role to play in supporting library and information management functions if they are truly interested in ensuring experiences and results of conservation projects are widely shared and disseminated.

Other approaches to resolving the information divide have included harnessing the growing open access movement (Laakso et al., 2011). The Budapest Open Access Initiative, which produced one of the earliest and most widely used definitions of open access in 2002, recommended two complementary strategies for achieving free and unrestricted online availability of peer-reviewed journal literature: self-archiving by authors (i.e. green open access) and open access journals (i.e. gold open access) (Budapest Open Access Initiative, 2002).

In gold open access, a paper is made immediately available for free by the publisher on the journal's website, an approach that has been recommended in a number of influential reviews (e.g. Finch, 2013). Much of the challenge of access to the conservation literature might be resolved were funders of conservation research to require that all research outputs be published as open access (Harnad et al., 2008), a move that some major funders (e.g. US National Institutes of Health, European Union) have already adopted. Such a shift would have costs, though. Some are financial: the costs of publication is sometimes shifted from the readers to the authors, which can leave the problem of authors or their sponsoring organizations not having sufficient funds to pay the article processing charges levied by publishers for publishing in an open access journal (Siler et al., 2018; Peterson et al., 2019). One top-end estimate for how much a shift to open access would cost (for conservation science papers 2000-2013) is \$51m (Fuller et al., 2014), funds that arguably could be better spent on conservation practice itself. However, if gold open access publishing could be shifted away from hybrid open access to full open access journals, there would be significant cost savings, since the former have been shown to be more expensive than the latter (Pinfield et al., 2015). Meanwhile, publishers like PeerJ offer waivers to researchers from low-income countries or alternative pricing models such as author memberships (https://peerj.com/about/FAQ/). Other costs are more pernicious, such as the proliferation of "predatory publishers" (Beall, 2013).

An alternative to gold open access is green open access, whereby authors deposit postacceptance but pre-formatting manuscripts into an online institutional or subject repository (Björk et al., 2014). Such systems have proven successful for disciplines such as physics, where arXiv respectively serves as a community-wide repository. In fact, conservation research can and has been deposited in arXiv and other preprint servers such as PeerJ Preprints, biorxiv, Zenodo, 
505 and preprints.org. The delayed and low levels of self-archiving by authors (Piwowar, 2018;

506 Harnad, 2006) would still present a challenge, though.

507

508 Open access is consistent with our findings regarding information seeking behaviour: the

509 conservation community as a whole, regardless of whether they have institutional access, turn to

510 free material online very frequently. However, it is also not clear whether open access would

511 save researchers time, given our finding that one of the impacts of lack of institutional access

512 was the amount of time spent finding literature through alternate means.

513

514 Our findings emerge out of our understanding of IUCN as a broadly useful proxy for the 515 conservation community; one example of how representative IUCN is of the conservation

516 community is that, in 2017, there were 114 IUCN NGO Members in the USA (combined annual

517 budget $>\$ 4.94 \mathrm{bn}$ ) compared to 532 US NGOs (combined annual budget $=\$ 4.90 \mathrm{bn}$ ) listed by

518 Charity Navigator (https://www.charitynavigator.org/) in the categories "Environment",

519 "Wildlife Conservation", "Zoos and Aquariums" and "Botanical Gardens" but not IUCN

520 Members (R. Merizalde unpublished data). Nevertheless, IUCN may not be perfectly

521 characteristic of the conservation community, and future work will require assessing the

522 information needs of the sectors that may have been left out of our study.

523

524 In the short-term, though, our results might provide guidance to the strategic development of

525 existing conservation libraries. Many such libraries are under severe budgetary constraints; our

526 findings regarding conservationists' "most desired" journals may help to guide purchasing

527 decisions for libraries without the resources to conduct a survey of their own user's preferred

528 journals. In addition, our findings regarding preferred reading formats suggests that conservation

529 libraries should continue to maintain hard copy books but could consider online-only access to

530 scientific journals. Finally, our results should strengthen the arguments as to the importance of

531 libraries in conservation agencies and institutions, given our strong evidence that those in the

532 conservation community that have library-facilitated access to the literature benefit greatly in

533 comparison to those that do not.

534

535 Conclusions

536 Access to scientific literature is a pernicious problem for more than half of the conservation

537 community, with numerous negative effects as a result. Lack of institutional access is the

538 primary predictor of disparities, followed by geographical location. In order to overcome the

539 information divide and their subsequent limitations on conservation work, our survey results

540 point towards solutions such as reinforcement of institutional and donor support to institutional

541 libraries and knowledge management as well as of open access initiatives. Future work could

542 include determining the levels of investments in libraries and information management as well as

543 the gradations of institutional access provided by the employers (i.e. institutions) of conservation 
544 professionals, to go beyond the IUCN constituency as well as individuals' self-reported measures 545 of access.

546

547 Acknowledgements

548 We are grateful to the 2,235 people through the IUCN constituency who completed the survey; 549 D. Murith for help with survey design; A. Rodrigues, R. Merizalde, and K. Holenstein for 550 providing references; to G. Fragoso, M. Hoffmann, R. Mounce, J. Siikamaki, and M. Lambert 551 for comments on the manuscript; and to K. Holzer, L. Patterson, and the two anonymous peer 552 reviewers for their thoughtful and constructive peer reviews.

553

554

555

556

557

558

559

560

561

562

563

564

565

566

567

568

569

570

571

572

573

574

575

576

577

578

579

580

References

Ai, C., \& Norton, E. C. (2003) Interaction terms in logit and probit models. Economics letters 80(1): 123129. https://doi.org/10.1016/S0165-1765(03)00032-6

Akaike, H. (1974) A new look at the statistical model identification. IEEE Transactions on Automatic Control 19 (6): 716-723, MR 0423716, doi:10.1109/TAC.1974.1100705.

Amano, T., Gonzalez-Varo, J.P., Sutherland, W.J. (2016) Languages are still a major barrier to global science. PLOS biology 14(12): e200093. https://doi.org/10.1371/journal.pbio.2000933

American Library Association. Definition of a library: general definition. Available at http://libguides.ala.org/library-definition (accessed 06 March 2020)

Barber, P.H., Ablan-Lagman, M.C.A., Berlinck, R.G., Cahyani, D., Crandall, E.D., RavagoGotanco, R., Juinio-Meñez, M.A., Mahardika, I.G., Shanker, K., Starger, C.J. Toha, A.H.A. (2014) Advancing biodiversity research in developing countries: the need for changing paradigms. Bulletin of Marine Science 90: 187-210. https://doi.org/10.5343/bms.2012.1108

Bartol, T. (2013) Information literacy and international capacity development initiatives in life sciences: AGORA, OARE, HINARI, ARDI (Research4Life - R4L). In Kurbanoglu, S., Grassian, E., Mizrachi, D., Catts, R., Špiranec, S., eds. Worldwide Commonalities and Challenges in Information Literacy Research and Practice. ECIL 2013. Communications in Computer and Information Science, vol 397. Springer, Cham, 338-344. https://doi.org/10.1007/978-3-319-03919-0_44

Beall, J. (2013) Predatory publishing is just one of the consequences of gold open access. Learned Publishing 26: 79-84. https://doi.org/10.1087/20130203

Bendezú-Quispe, G., Nieto-Gutiérrez, W., Pacheco-Mendoza, J., Taype-Rondan, A. (2016) SciHub and medical practice: an ethical dilemma in Peru. The Lancet Global Health 4(9): PE608. https://doi.org/10.1016/S2214-109X(16)30188-7

Peer] reviewing PDF | (2019:11:43492:2:1:NEW 18 May 2020) 
581 Björk, B.C., Laakso, M., Welling, P., Paetau, P. (2014) Anatomy of green open access. Journal

582

583

584

585

586

587

588

589

590

591

592

593

594

595

596

597

598

599

600

601

602

603

604

605

606

607

608

609

610

611

612

613

614

615

616

617

618

619

620 of the Association for Information Science and Technology 65: 237-250. https://doi.org/10.1002/asi.22963

Bohannon, J. (2016) Who's downloading pirated papers? Everyone. Available at https://doi.org/10.1126/science.aaf5664

Boudry, C., Alvarez-Muñoz, P., Arencibia-Jorge, R., Ayena, D., Brouwer, N.J., Chaudhuri, Z., Chawner, B., Epee, E., Erraïs, K., Fotouhi, A., Gharaibeh, A.M., Hassanein, D.H., HerwigCarl, M.C., Howard, K., Kaimbo Wa Kaimbo, D., Laughrea, P., Lopez, F.A., MachinMastromatteo, J.D., Malerbi, F.K., Amadou Ndiaye, P., Noor, N.A., Pacheco-Mendoza, J., Papastefanou, V.P., Shah, M., Shields, C.L., Wang, Y.X., Yartsev, V., Mouriaux, F. (2019) Worldwide inequality in access to full text scientific articles: the example of ophthalmology. PeerJ:e7850. https://doi.org/10.7717/peerj.7850

Budapest Open Access Initiative (2002) Read the Budapest Open Access Initiative. Available at https://www.budapestopenaccessinitiative.org/read (accessed 6 March 2020)

Burton, A. (2011) Sharing science: enabling global access to the scientific literature. Environmental Health Perspectives 119(12). https://doi.org/10.1289/ehp.119-a520

Büttikofer, J. (1946) Rapport sur la Conférence pour la Protection Internationale de la Nature = Report on the Conference for the International Protection of Nature. Basel: The Swiss League for the Protection of Nature

Büttikofer, J. (1947) Conférence internationale pour la protection de la nature, Brunnen, 28 juin - 3 juillet 1947: procès-verbaux, résolutions et rapports = International Conference for the Protection of Nature, Brunnen, June 28th-July 3rd 1947 : proceedings, resolutions and reports. Basel: Provisional International Union for the Protection of Nature

Ceci, S.J., Williams, W.M. (2011) Understanding current causes of women's underrepresentation in science. Proceedings of the National Academy of Sciences of the U.S.A. 108(8): 31573162. https://doi.org/10.1073/pnas.1014871108

Chan, L., Kirsop, B., Arunachalam, S. (2011) Towards open and equitable access to research and knowledge for development. PLoS Medicine 8(3): e1001016. https://doi.org/10.1371/journal.pmed.1001016

Chan, L., Gray, E., Kahn, R. (2012) Open Access and Development: journals and beyond. Brighton: Institute of Development Studies (IDS)

Coloma, J., Harris, E. (2005) Open-Access Science: A Necessity for Global Public Health. PLoS Pathog 1(2): e21. https://doi.org/10.1371/journal.ppat.0010021

Connaway, L.S., Dickey, T.J., Radford, M.L. (2011) "If it is too inconvenient I'm not going after it:" Convenience as a critical factor in information-seeking behaviors. Library \& Information Science Research 33: 179-190. https://doi.org/10.1016/j.lisr.2010.12.002

Cvitanovic, C., Fulton C.J., Wilson, S.K., van Kerkhoff, L., Cripps, I.L., Muthiga, N. (2014). Utility of primary scientific literature to environmental managers: An international case study on coral-dominated marine protected areas. Ocean and coastal management 102: 72-78. https://doi.org/10.1016/j.ocecoaman.2014.09.003 
621 Cook, C.N., Hockings, M., Carter, R.W. (2010) Conservation in the dark? The information used

622

623

624

625

626

627

628

629

630

631

632

633

634

635

636

637

638

639

640

641

642

643

644

645

646

647

648

649

650

651

652

653

654

655

656

657

658

659 to support management decisions. Frontiers in Ecology and the Environment 8(4): 181186. https://doi.org/10.1890/090020

Cullen, P., Cottingham, P., Doolan, J., Edgar, B., Ellis, C., Fisher, M., Flett, D., Johnson, D., Sealie, L., Stocklmayer, S., Vanclay, F., Whittington, J. (2001) Knowledge seeking strategies of natural resource professional : synthesis of a workshop held in Bungendore, NSW from 5-7th June 2000. Technical report 2/2001. Cooperative Research Centre for Freshwater Ecology.

Fabian, Y., Bollmann, K., Brang, P., Heiri, C., Olschewski, R., Rigling, A., Stofer, S., Holderegger, R. (2019) How to close the science-practice gap in nature conservation? Information used by practitioners. Biological Conservation 235: 93-101. https://doi.org/10.1016/j.biocon.2019.04.011

Finch, D.J. (2013) Accessibility, sustainability, excellence: the UK approach to Open Access. Information Services \& Use 33(1): 11-18. https://doi.org/10.3233/ISU-130687

Fisher, M. (2015) A literature for all conservationists, everywhere? Oryx 49(1): 1-2. https://doi.org/10.1017/S0030605314001094

Fonseca, G., Benson, P.J. (2003) Biodiversity conservation demands open access. PLoS Biology 1(2): e46. https://doi.org/10.1371/journal.pbio.0000046

Fuller, R.A., Lee, J.R., Watson, J.E.M. (2014) Achieving open access to conservation science. Conservation Biology 28(6): 1550-1557. https://doi.org/10.1111/cobi.12346

Gaulé, P. (2009) Access to scientific literature in India. Journal of the American Society for Information Science and Technology 60(12): 2548-2553. https://doi.org/10.1002/asi.21195

Godlee, F., Pakenham-Walsh, N., Ncayiyana, D., Cohen, B., Packer, A. (2004) Can we achieve health information for all by 2015? The Lancet 364(9430): 295-300. https://doi.org/10.1016/S0140-6736(04)16681-6

Gossa, C., Fisher, M., Milner-Gulland, E.J. (2015) The research-implementation gap: how practitioners and researchers from developing countries perceive the role of peer-reviewed literature in conservation science. Oryx 49(1): 80-87. https://doi.org/10.1017/S0030605313001634

Greshake, B. (2016) Correlating the Sci-Hub data with World Bank indicators and identifying academic use. Available at https://hewinnower.com/papers/4715-correlating-the-sci-hubdata-with-world-bank-indicators-and-identifying-academic-use.

Harnad, S. Maximising research impact through institutional and national open-access selfarchiving mandates. Jeffrey, Keith (ed.) CRIS2006. Current Research Information Systems: Open Access Institutional Repositories, Bergen, Norway. 11 - 13 May 2006.

Harnad, S., Brody, T., Vallieres, F., Carr, L., Hitchcock, S., Gingras, Y., Oppenheim, C., Hajjem, C., Hilf, E.R. (2008) The access/impact problem and the green and gold roads to open access: an update. Serials Review 34(1): 36-40. https://doi.org/10.1016/j.serrev.2007.12.005 
660 Harris, M.R. (2005) The librarian's roles in the systematic review process: a case study. $J$ Med

661

662

663

664

665

666

667

668

669

670

671

672

673

674

675

676

677

678

679

680

681

682

683

684

685

686

687

688

689

690

691

692

693

694

695

696

697

698

699 Libr Assoc. 93(1): 81-87.

Himmelstein, D.S., Rodriguez Romero, A., Levernier, J.G., Munro, T.A., Reid McLaughlin, S., Greshake Tzovaras, B., Greene, C.S. (2017) Research: Sci-Hub provides access to nearly all scholarly literature. eLife. https://doi.org/10.7554/eLife.32822

Horton, R. (2000) North and South: bridging the information gap. The Lancet 355(9222): 22312236. https://doi.org/10.1016/S0140-6736(00)02414-4

IUCN (1951) Proceedings and reports of the second session of the General Assembly held in Brussels, 18-23 October 1950 in the Institut de Sociologie Solvay de l'Université Libre de Bruxelles. Brussels: IUCN

Jones, T.H., Hanney, S., Buxton, M.J. (2006) The journals of importance to UK clinicians: a questionnaire survey of surgeons. BMC Medical Informatics and Decision Making 6:24. https://doi.org/10.1186/1472-6947-6-24

Karlsson, S., Srebotnjak, T., Gonzales, P. (2007) Understanding the North-South knowledge divide and its implications for policy: a quantitative analysis of the generation of scientific knowledge in the environmental sciences. Environmental Science \& Policy 10: 668-684. https://doi.org/10.1016/j.envsci.2007.04.001

Kaur, A. (2012). Academics' attitudes towards use of electronic journals: A case study of Punjab and Chandigarh. The International Information \& Library Review 44(4): 182-193. https://doi.org/10.1016/j.iilr.2012.09.003

Laakso, M., Welling, P., Bukvova, H., Nyman, L., Björk, B.C., Hedlund, T. (2011) The development of open access journal publishing from 1993 to 2009. PloS ONE 6(6): p.e20961. https://doi.org/10.1371/journal.pone.0020961

Leckie, G.J., Pettigrew, K.E., and Sylvain, C. (1996). Modeling the information seeking of professionals: A general model derived from research on engineers, health care professionals, and lawyers. Library Quarterly 66 (2): 161-193. https://doi.org/10.1086/602864

Nuñez, Martin A., Barlow, J., Cadotte, M., Lucas, K., Newton, E., Pettorelli, N., Stephens, P.A. (2019) Assessing the uneven global distribution of readership, submissions and publications in applied ecology: obvious problems without obvious solutions. Journal of Applied Ecology 56:4-9. https://doi.org/10.1111/1365-2664.13319

Pasgaard, M., Strange, N. (2013) A quantitative analysis of the causes of the global climate change research distribution. Global Environmental Change 23(6): 1684-1693. https://doi.org/10.1016/j.gloenvcha.2013.08.013

Peterson, A.T., Anderson, R.P., Beger, M., Bolliger, J., Brotons, L., Burridge, C.P., Cobos, M.E., Cuervo-Robayo, A.P., Di Minin, E., Diez, J., Elith, J., Embling, C.B., Escobar, L.E., Essl, F., Feeley, K.J., Hawkes, L., Jiménez-García, D., Jimenez, L. Green, D.M., Knop, E., Kühn, I., Lahoz-Monfort, J.J., Lira-Noriega, A., Lobo, J.M., Loyola, R., Mac Nally, R., Machado-Stredel, F., Martínez-Meyer, E., McCarthy, M., Merow, C., Nori, J., NuñezPenichet, C., Osorio-Olvera, L., Pyšek, P., Rejmánek, M., Ricciardi, A., Robertson, M., 
700

701

702

703

704

705

706

707

708

709

710

711

712

713

714

715

716

717

718

719

720

721

722

723

724

725

726

727

728

729

730

731

732

733

734

735

736

737

738

739

740

Rojas Soto, O. Romero-Alvarez, D., Roura-Pascual, N., Santini, L., Schoeman, D.S., Schröder, B., Soberon, J., Strubbe, D., Thuiller, W., Traveset, A., Treml, E.A., Václavik, T., Varela, S., Watson, J.E.M., Wiersma, Y., Wintle, B., Yanez-Arena, C., Zurell, D. (2019). Open access solutions for biodiversity journals: Do not replace one problem with another. Diversity and distributions 25(1):5-8. https://doi.org/10.1111/ddi.12885

Pinfield, S., Salter, J., Bath, P.A. (2015) The "total cost of publication" in a hybrid open-access environment: Institutional approaches to funding journal article-processing charges in combination with subscriptions. Journal of the Association for Information Science and Technology 67(7): 1751-1766. https://doi.org/10.1002/asi.23446

Piwowar, H., Priem, J., Larivière, V., Alperin, J.P., Matthias, L., Norlander, B., Farley, A., West, J., Haustein, S. (2018) The state of OA: a large-scale analysis of the prevalence and impact of Open Access articles. PeerJ 6:e4375. https://doi.org/10.7717/peerj.4375

Pullin, A.S., Knight, T.M. (2003) Support for decision making in conservation practice: an evidence-based approach. Journal for Nature Conservation 11(2): 83-90. https://doi.org/10.1078/1617-1381-00040

R Core Team (2017). R: A language and environment for statistical computing. R Foundation for Statistical Computing, Vienna, Austria. Available at https:/www.R-project.org/.

Rafidimanantsoa, H.P., Poudyal, M., Ramamonjisoa, B.S., Gordon Jones, J.P. (2018) Mind the gap: the use of research in protected area management in Madagascar. Madagascar Conservation \& Development 13(1): 15-24. https://doi.org/10.4314/mcd.v13i1.3

Research Information Network (2009) E-journals: their use, value and impact. London: Research Information Network.

Rodrigues, A.S., Gray, C.L., Crowter, B.J., Ewers, R.M., Stuart, S.N., Whitten, T., Manica, A., (2010) A global assessment of amphibian taxonomic effort and expertise. BioScience 60(10): 798-806. https://doi.org/10.1525/bio.2010.60.10.6

Roy, S., Smith, G., Russell, J.C. (2009). The eradication of invasive mammal species: can adaptive resource management fill the gaps in our knowledge? Human-Wildlife Conflicts 3(1): 30-40.

Sayer, J., Campbell, B. (2004). The science of sustainable development: Local livelihoods and the global environment. Cambridge: Cambridge University Press.

Seavy, N.E., Howell, C.A. (2010). How can we improve information delivery to support conservation and restoration decisions? Biodiversity Conservation 19(5):1261-1267.

Sheikheldin, G., Krantzberg, G., Schaefer, K. (2010) Science-seeking behaviour of conservation authorities in Ontario. Environmental Management 45:912-921.

Siler, K., Haustein, S., Smith, E., Larivière, V., Alperin, J.P. (2018) Authorial and institutional stratification in open access publishing: the case of global health research. PeerJ 6:e4269. https://doi.org/10.7717/peerj.4269

Smith, H., Bukirwa, H., Mukasa, O., Snell, P., Adeh-Nsoh, S., Mbuyita, S., Honorati, M., Orji, B., Garner, P. (2007) Access to electronic health knowledge in five countries in Africa: a descriptive study. BMC Health Services Research 7:72. https://doi.org/10.1186/1472-69637-72 
741 Steiner Davis, M.L.E., Tenopir, C., Allard, S., Frame, M.T. (2014) Facilitating access to

742 biodiversity information; A survey of users' needs and practices. Environmental

743 Management 53(3): 690-701.

744 Tenopir, C., Christian, L., Kaufamn, J. (2019) Seeking, reading, and use of scholarly articles: an

745 international study of perceptions and behavior of researchers. Publications 7(1), 18.

746 https://doi.org/10.3390/publications 7010018

747 Villafuerte-Gálvez, J., Curioso, W.H., Gayoso, O. (2007) Biomedical journals and global

748 poverty: Is HINARI a step backwards? PLOS Medicine 4(6): 220.

$749 \quad$ https://doi.org/10.1371/journal.pmed.0040220

750 Walsh, J.C., Dicks, L.V., Sutherland, W.J. (2015) The effect of scientific evidence on

751 conservation practitioners' management decisions. Conservation Biology 29(1): 88-98.

752 https://doi.org/10.1111/cobi.12370

753 Wilson, K.A., Auerbach, N.A., Sam, K., Magini, A.G., Moss, A.S.L., Langhans, S.D., Budiharta, 754 S., Terzano, D., Meijaard, E. (2016) Conservation research is not happening where it is

755 most needed. PLoS Biology 14(3): e1002413. https://doi.org/10.1371/journal.pbio.1002413 


\section{Table $\mathbf{1}$ (on next page)}

Survey response rate among all to whom the survey was directly distributed, by IUCN component. 


\begin{tabular}{|l|r|r|r|}
\hline Respondent type & $\begin{array}{l}\text { Number of } \\
\text { Responses }\end{array}$ & Total sent & $\begin{array}{l}\text { Response } \\
\text { rate }\end{array}$ \\
\hline All respondents & 2285 & 17166 & $13.31 \%$ \\
\hline Any Member & 504 & 1609 & $31.32 \%$ \\
\hline State Member & 68 & Unknown & Unknown \\
\hline IUCN Government Agency & & & \\
Member & 78 & Unknown & Unknown \\
\hline IUCN International NGO Member & 124 & Unknown & Unknown \\
\hline IUCN National NGO Member & 237 & Unknown & Unknown \\
\hline IUCN Affiliate Member & 53 & Unknown & Unknown \\
\hline IUCN CEC member & 155 & 1152 & $13.45 \%$ \\
\hline IUCN CEESP member & 127 & 578 & $21.97 \%$ \\
\hline IUCN CEM member & 165 & 968 & $17.05 \%$ \\
\hline IUCN SSC member & 1050 & 9528 & $11.02 \%$ \\
\hline IUCN WCEL member & 77 & 1377 & $5.59 \%$ \\
\hline IUCN WCPA member & 407 & 2594 & $15.69 \%$ \\
\hline IUCN Secretariat staff & 155 & 1057 & $14.66 \%$ \\
\hline
\end{tabular}

1 


\section{Table 2 (on next page)}

Summary of the final binomial logistic regression model.

Coef. shows the change in the log-odds for a change between two cases of the same variable since they are all categorical (eg. moving female to male). In the case of region, the comparison is between each region code and Africa, since that region has the lowest log odds of easy access. The comparison reference level (Africa, Female, no Institutional Access) is not shown. Odds ra. is the odds ratio. Std. Err. is the standard error of the estimate, $z$ and $p$ are the Wald z-statistic and associated $p$-values. 


\begin{tabular}{|c|c|c|c|c|c|}
\hline Ease of Access & Coef. & Odds ra. & Std. Err. & $\mathbf{z}$ & $\mathbf{p}$ \\
\hline Model Intercept & -1.5754 & .2069 & 0.1711 & -9.207 & $\begin{array}{r}<2 \mathrm{e}- \\
16 * * *\end{array}$ \\
\hline Region: Asia-Pacific & 0.2610 & 1.2982 & 0.1819 & 1.435 & 0.151 \\
\hline Region: Eastern Europe & 0.2266 & 1.2544 & 0.2729 & 0.831 & 0.406 \\
\hline $\begin{array}{r}\text { Region: Latin America and } \\
\text { Caribbean }\end{array}$ & 0.1824 & 1.2001 & 0.1940 & 0.940 & 0.345 \\
\hline $\begin{array}{r}\text { Region: Western Europe and } \\
\text { Others }\end{array}$ & 0.5467 & 1.7275 & 0.1587 & 3.445 & $\begin{array}{r}0.00057 \\
2 * * *\end{array}$ \\
\hline Gender: Male & 0.3208 & 1.3782 & 0.1117 & 2.873 & $\begin{array}{r}0.00407 \\
* * *\end{array}$ \\
\hline Institutional Access: Yes & 1.9251 & 6.8558 & 0.1028 & 18.723 & $\begin{array}{r}<2 \mathrm{e}- \\
16 * * *\end{array}$ \\
\hline
\end{tabular}


Table 3 (on next page)

Tukey post hoc contrasts between regions. 
1

\begin{tabular}{r|rrrr} 
Contrast & Est. & Std.Err. & z & p \\
\hline Asia-Pacific - Africa & 0.2610 & 0.1819 & 1.4350 & 0.5891 \\
Eastern Europe - Africa & 0.2267 & 0.2729 & 0.8310 & 0.9161 \\
Latin America and Caribbean - Africa & 0.1824 & 0.1940 & 0.9400 & 0.8739 \\
Western Europe and Others - Africa & $\mathbf{0 . 5 4 6 7}$ & $\mathbf{0 . 1 5 8 7}$ & $\mathbf{3 . 4 4 5 0}$ & $\mathbf{0 . 0 0 4 8}$ \\
Eastern Europe - Asia Pacific & -0.0344 & 0.2620 & -0.1310 & 0.9999 \\
Latin America and Caribbean - Asia-Pacific & -0.0786 & 0.1781 & -0.4410 & 0.9915 \\
Western Europe and Others - Asia Pacific & 0.2857 & 0.1388 & 2.0580 & 0.2259 \\
Latin America and Caribbean - Eastern & & & & \\
Europe & -0.0442 & 0.2698 & -0.1640 & 0.9998 \\
Western Europe and Others - Eastern & & & & \\
Europe & 0.3200 & 0.2458 & 1.3020 & 0.6759 \\
Western Europe and Others - Latin America & & & & \\
and Caribbean & 0.3643 & 0.1519 & 2.3990 & 0.1081
\end{tabular}


Table 4 (on next page)

Disciplinary variation in proportion of respondents with institutional literature access. 


\begin{tabular}{|l|l|l|l|}
\hline IUCN Commission & $\begin{array}{l}\text { Disciplinary } \\
\text { specialisation }\end{array}$ & $\begin{array}{l}\text { Responses to Q9 } \\
\text { (number) }\end{array}$ & $\begin{array}{l}\text { Institutional access } \\
\text { (percentage) }\end{array}$ \\
\hline $\begin{array}{l}\text { Commission on Education } \\
\text { and Communication (CEC) }\end{array}$ & $\begin{array}{l}\text { Environmental education } \\
\text { and communication }\end{array}$ & 125 & 52 \\
\hline $\begin{array}{l}\text { Commission on } \\
\text { Environmental, Economic, } \\
\text { and Social Policy (CEESP) }\end{array}$ & $\begin{array}{l}\text { Environmental social } \\
\text { science }\end{array}$ & 112 & 54 \\
\hline $\begin{array}{l}\text { Commission on Ecosystems } \\
\text { Management (CEM) }\end{array}$ & Ecosystem conservation & 156 & 54 \\
\hline $\begin{array}{l}\text { World Commission on } \\
\text { Environmental Law } \\
\text { (WCEL) }\end{array}$ & Environmental law & 58 & 60 \\
\hline $\begin{array}{l}\text { World Commission on } \\
\text { Protected Areas(WCPA) }\end{array}$ & Protected areas & 370 & 42 \\
\hline $\begin{array}{l}\text { Species Survival } \\
\text { Commission (SSC) }\end{array}$ & Species conservation & 950 & 58 \\
\hline
\end{tabular}

1 


\section{Table 5 (on next page)}

Variation by sector in proportion of respondents with institutional literature access. 


\begin{tabular}{|l|l|l|}
\hline Sector & $\begin{array}{l}\text { Responses to } \\
\text { Q9 (number) }\end{array}$ & $\begin{array}{l}\text { Institutional access } \\
\text { (percentage) }\end{array}$ \\
\hline IUCN Secretariat & 132 & 28 \\
\hline State and/or Government Agency Members & 113 & 58 \\
\hline International NGO Members & 108 & 45 \\
\hline National NGO Members & 207 & 48 \\
\hline
\end{tabular}

1 


\section{Table 6(on next page)}

Top 20 journals mentioned by survey respondents as having the potential to have the largest impact on IUCN-related work if easy access to them could be obtained. 


\begin{tabular}{|r|l|}
\hline Rank & Journal title \\
\hline 1 & Conservation Biology \\
\hline 2 & Nature \\
\hline 3 & Biological Conservation \\
\hline 4 & Science \\
\hline 5 & Zootaxa \\
\hline 6 & Oryx \\
\hline 7 & Journal of Wildlife Management \\
\hline 8 & Biodiversity and Conservation \\
\hline 9 & Parks \\
\hline 10 & Ecology \\
\hline 11 & Molecular Ecology \\
\hline 12 & PLoS ONE \\
\hline 13 & Journal of Applied Ecology \\
\hline 14 & Zoo Biology \\
\hline 15 & Journal of Environmental Management \\
\hline 16 & Marine Mammal Science \\
\hline 17 & Conservation Letters \\
\hline 18 & Journal of Mammology \\
\hline 19 & Marine Ecology Progress Series \\
\hline 20 & Chelonian Conservation and Biology \\
\hline
\end{tabular}

1 
Figure 1

Required frequency of access to scientific literature $(n=2285)$.

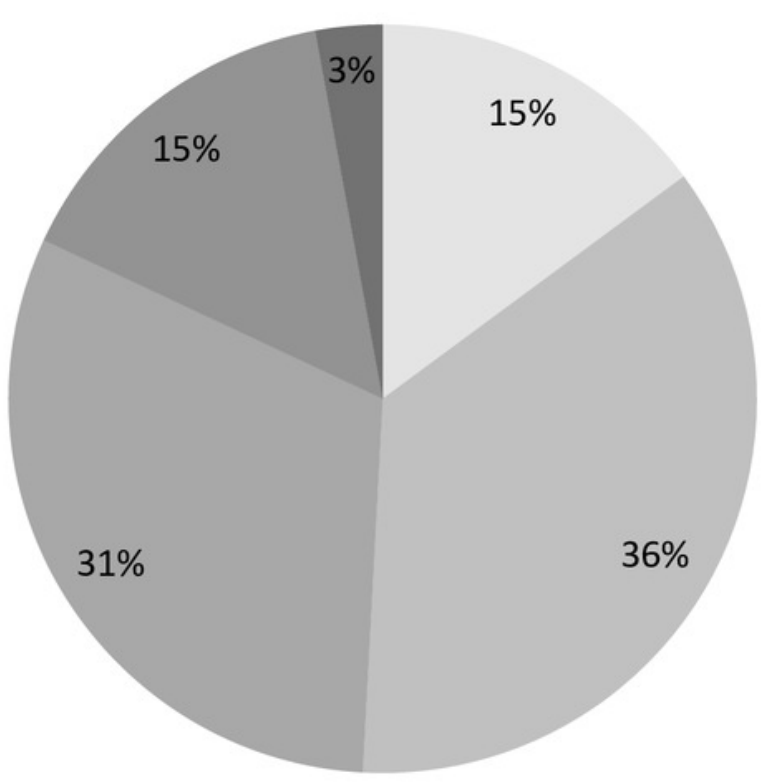

Very frequently (daily)

Frequently (once a week)

- Sometimes (once a month)

- Infrequently

never 
Figure 2

Ease of access to scientific literature in the conservation community $(n=2,004)$

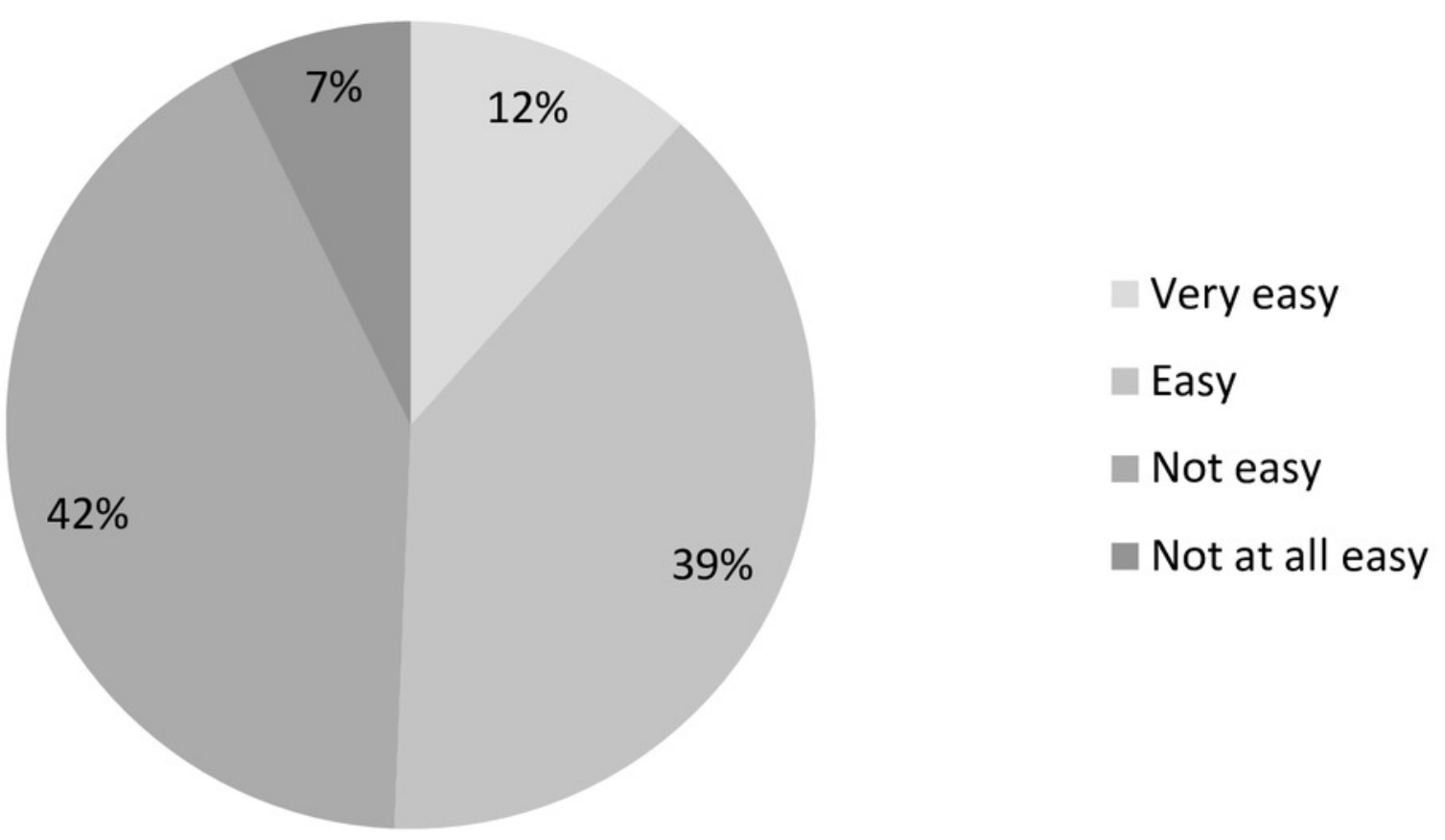


Figure 3

Ease of access to scientific literature among those in the conservation community according to whether they reported having institutional access to scientific literature ( $\mathrm{n}$ $=2,004)$.

\begin{tabular}{|c|c|c|c|c|c|c|}
\hline \multirow{3}{*}{$\begin{array}{l}\text { With institutional access } \\
\text { Without institutional access }\end{array}$} & & & & & & \multirow{2}{*}{$\begin{array}{l}\text { Very easy } \\
\text { Easy } \\
\text { Not easy }\end{array}$} \\
\hline & & & & & & \\
\hline & $20 \%$ & $40 \%$ & $60 \%$ & $80 \%$ & $100 \%$ & Not at all easy \\
\hline
\end{tabular}


Figure 4

Survey respondents grouped by region $(n=2254)$.

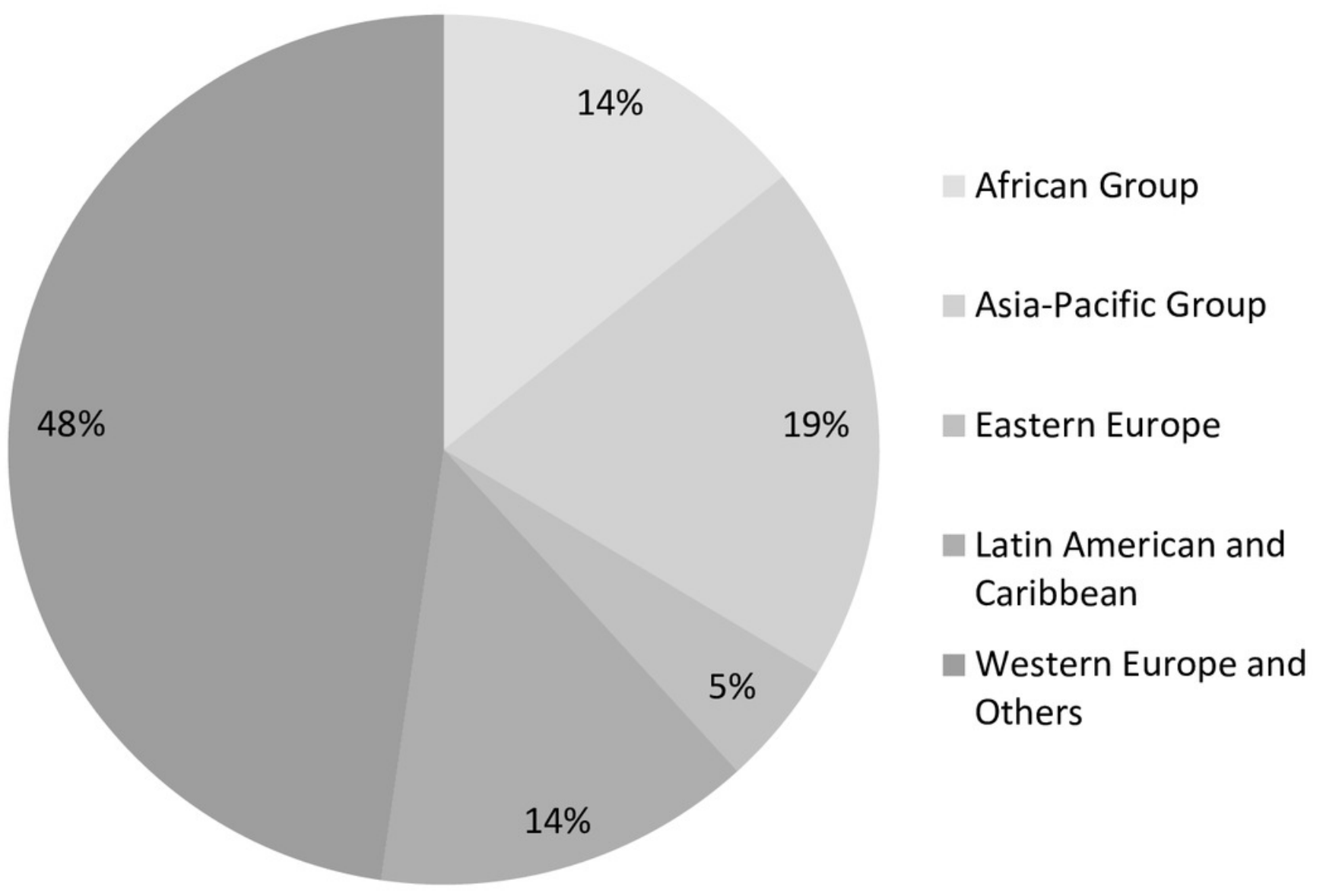


Figure 5

Levels of ease of access to scientific literature for IUCN-related work among respondents from the five UN regions $(n=1,982)$.

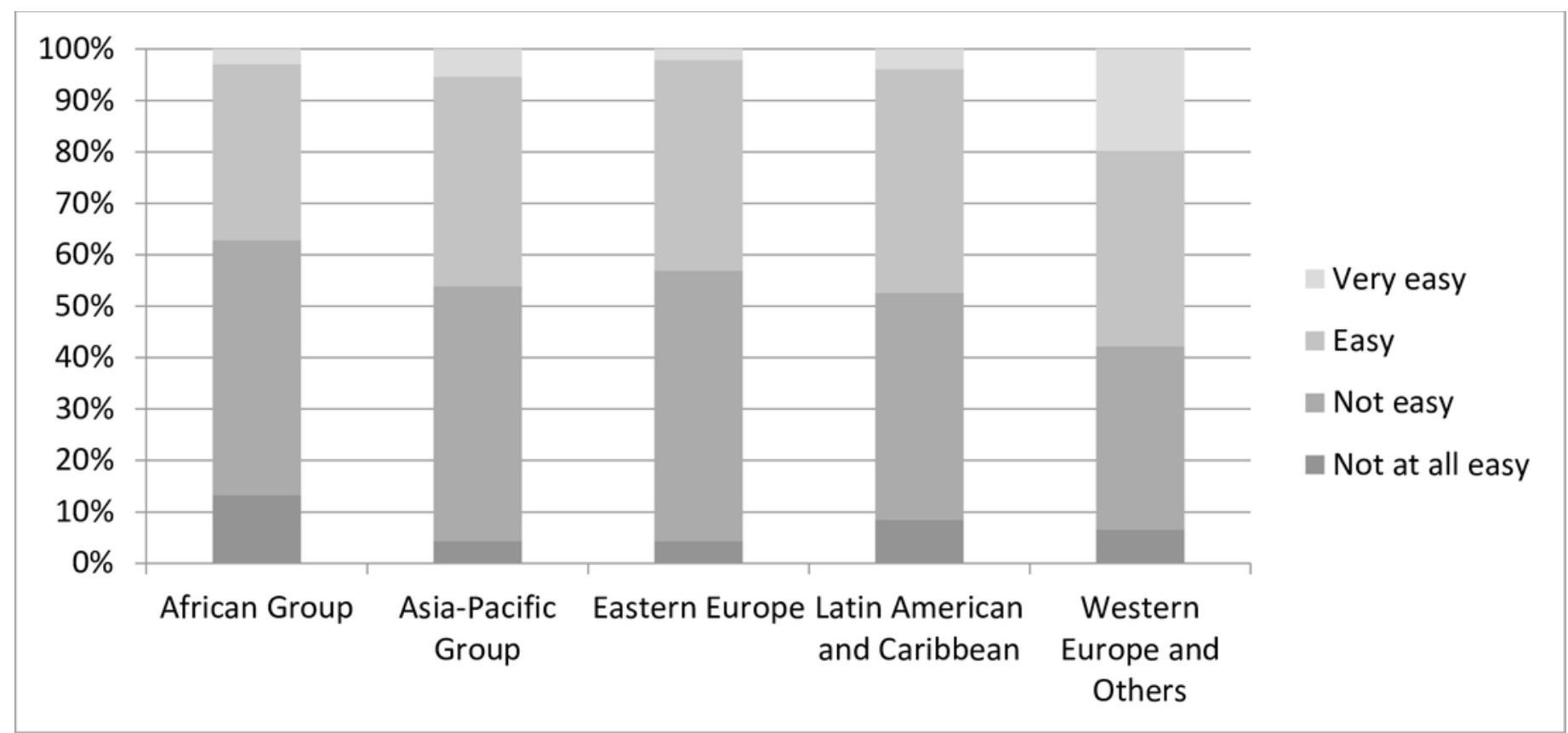




\section{Figure 6}

Levels of reported online institutional access to scientific literature among respondents from the five UN regions $(n=1982)$.

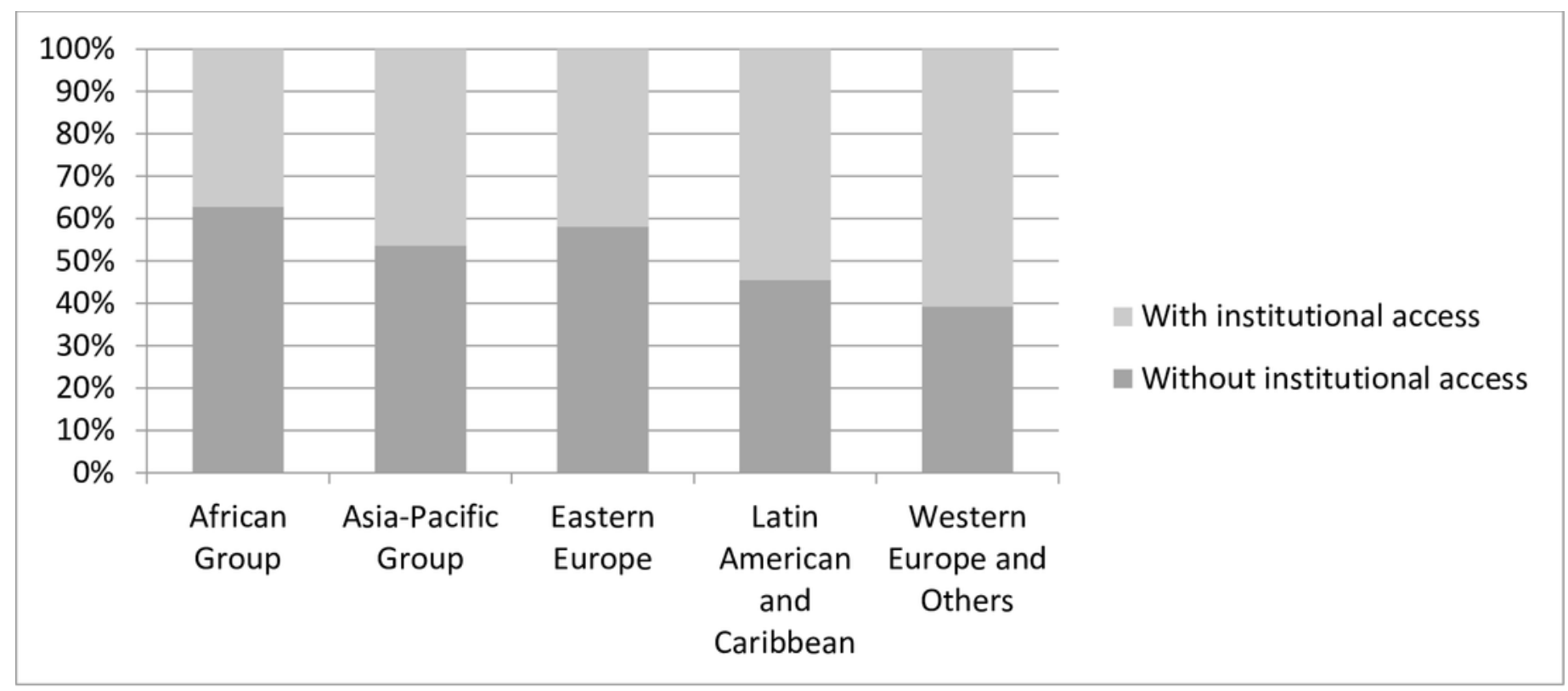


Figure 7

Importance of easy access to scientific literature $(n=2,004)$.

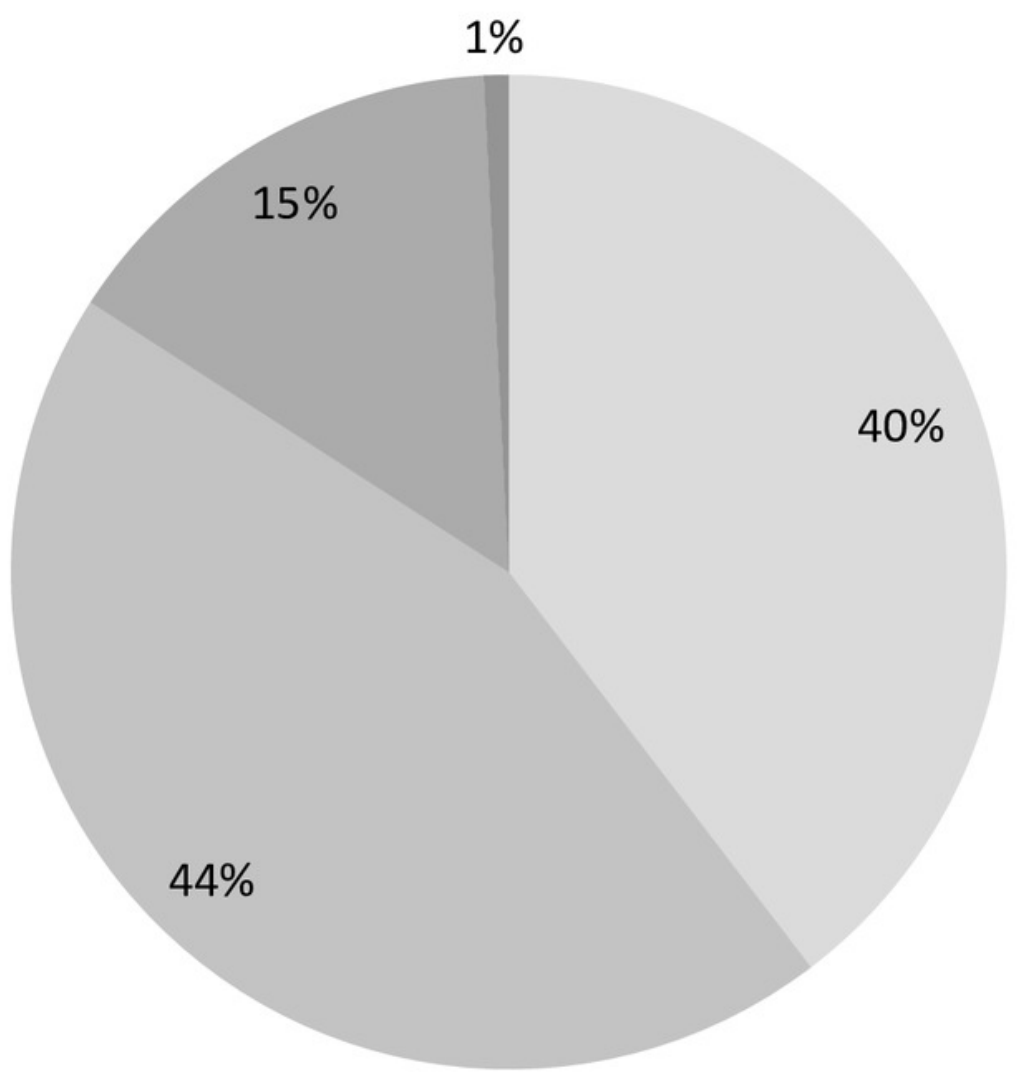

\section{Essential}

Very important

Somewhat important

Not at all important 


\section{Figure 8}

Impact on IUCN-related work of not having institutional access to scientific literature online ( $n=938)$.

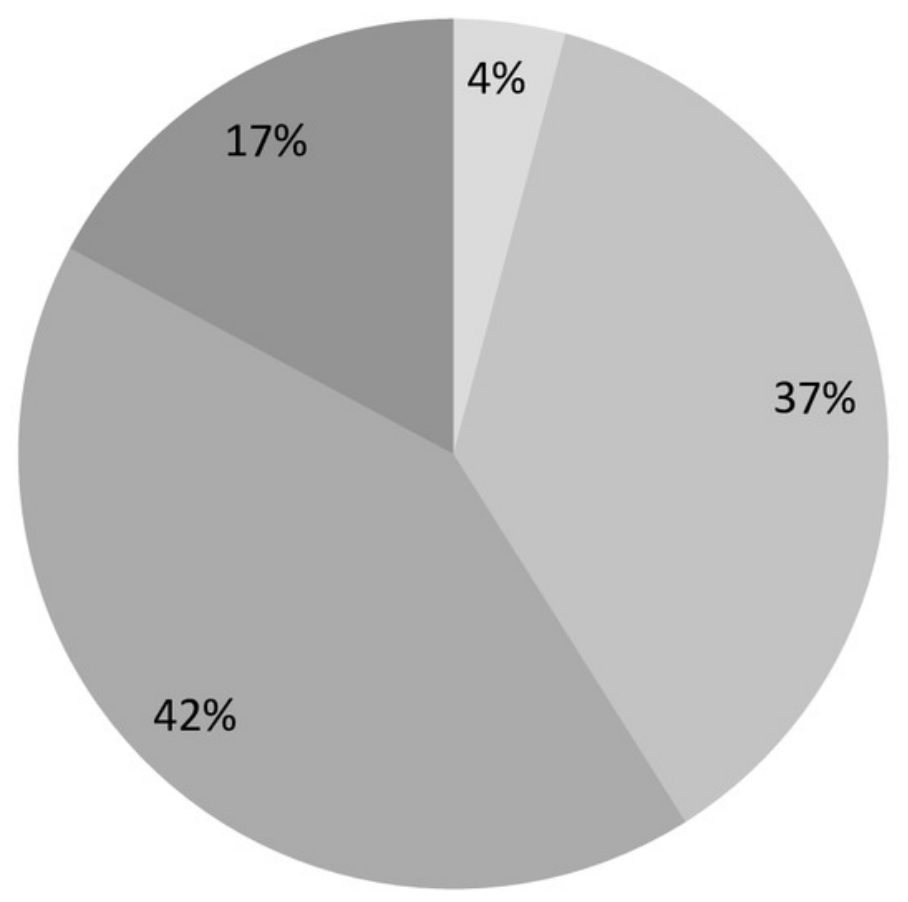

No impact at all

- Slight negative impact

Moderate negative impact

Great negative impact 
Figure 9

Effect on quality of IUCN-related work if institutional access to scientific literature online were obtained $(n=938)$.

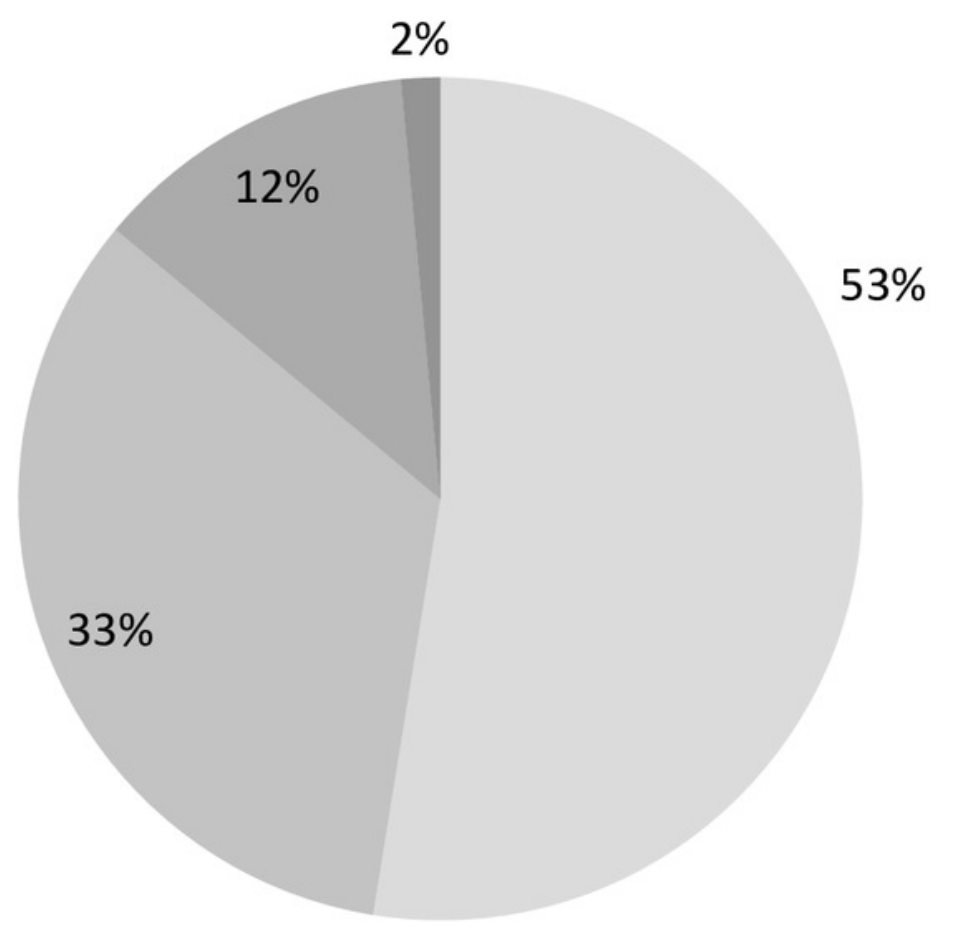

Great positive effect

Moderate positive effect

Slight positive effect

No effect at all 


\section{Figure 10}

How frequently those reporting no institutional access would use it for IUCN-related work if they had it $(n=918)$.

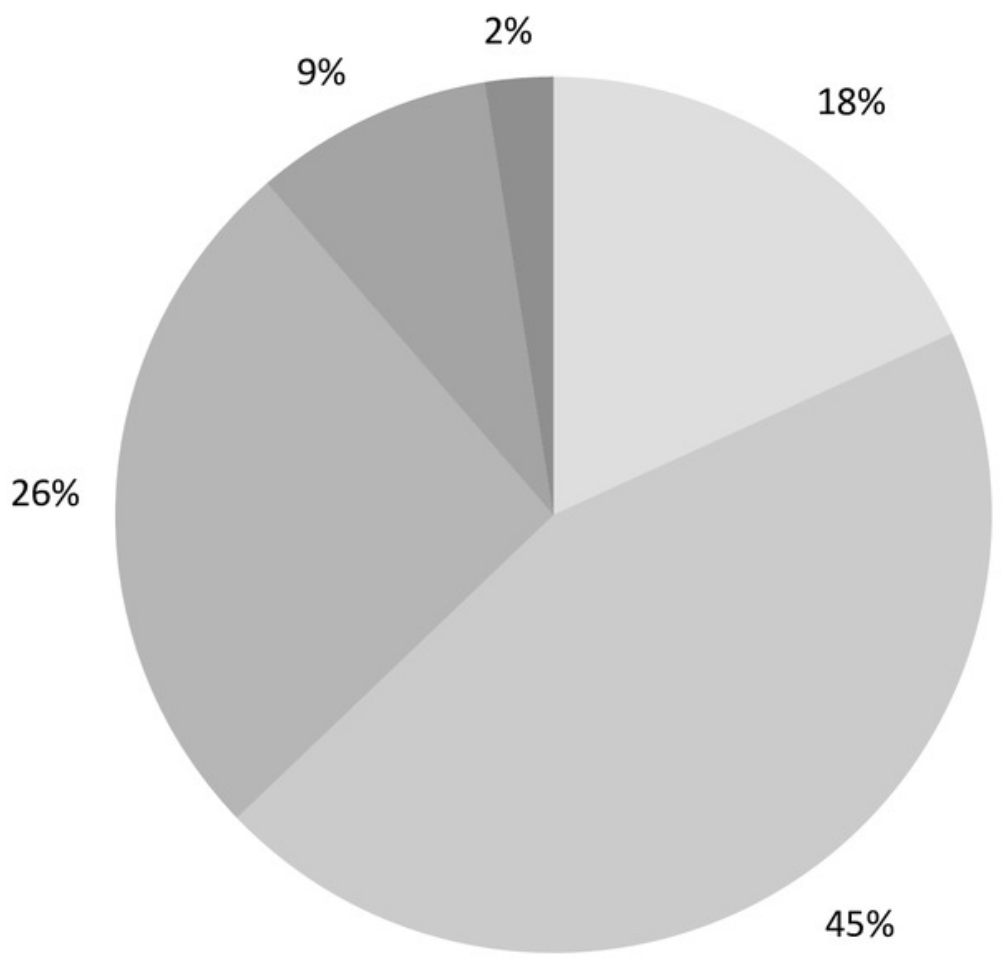

Very frequently (daily)

- Frequently (once a week)

- Sometimes (once a month)

- Infrequently

Never 


\section{Figure 11}

Frequency of accessing literature through various information pathways among respondents with and without institutional access $(n=2,004)$.

From light to dark grey: very frequently (daily); frequently (once a week); sometimes (once a month); infrequently; never or not available. 
A. I use the library of my own institution.

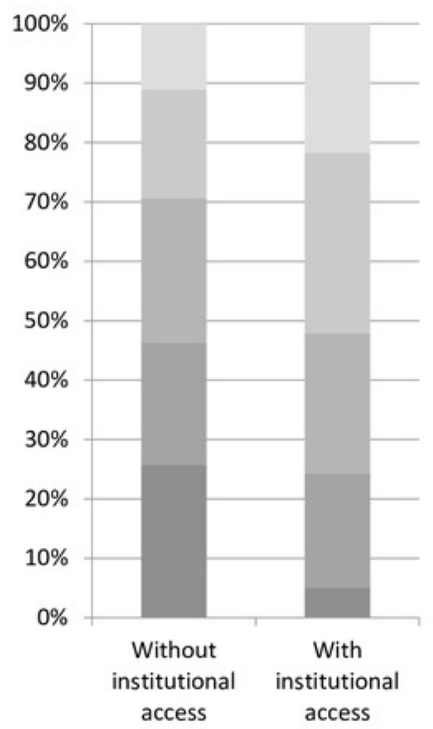

E. I request journal articles from the author.

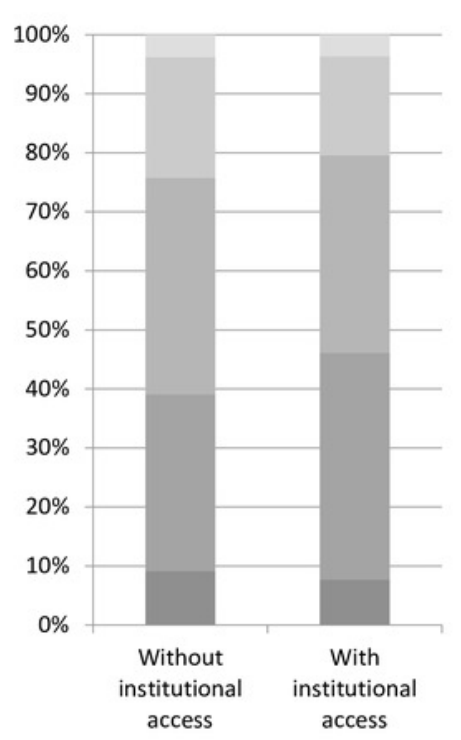

B. I visit a local library (public, academic, etc.) to read scientific literature in print.

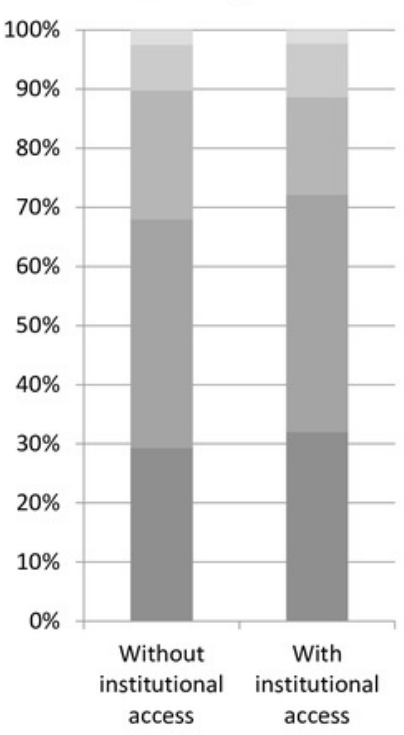

F. I access scientific literature through my own personal subscription to individual journals.

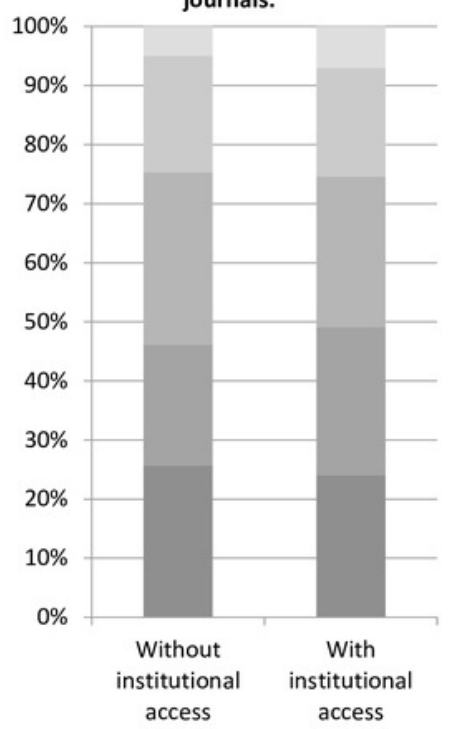

C. I use my institutional access to scientific literature online.

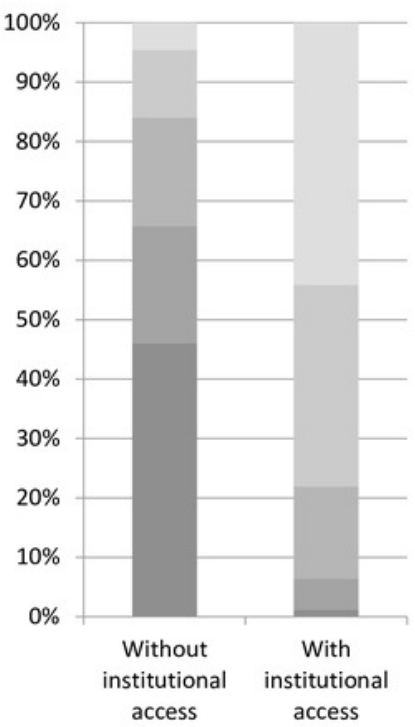

G. I ask a friend or colleague whom I know has access to scientific literature online.

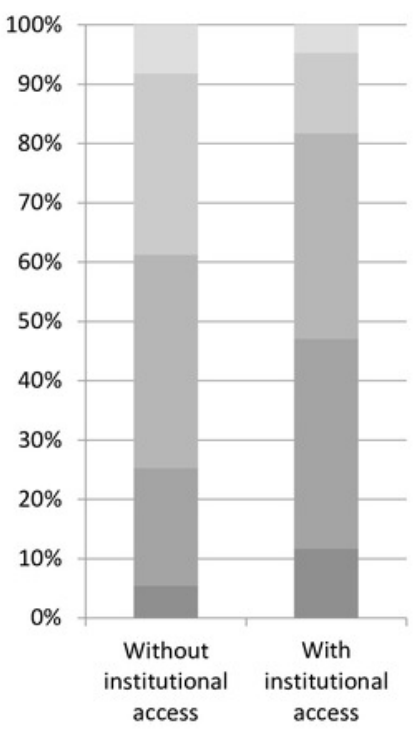

D: I request journal articles from the IUCN Librarian.

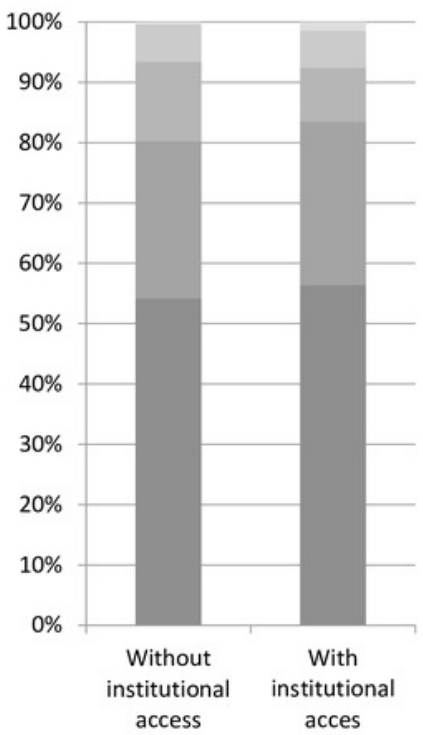

H. I access whatever I can find online for free (via Google Scholar, open-access journals, ResearchGate, etc.)

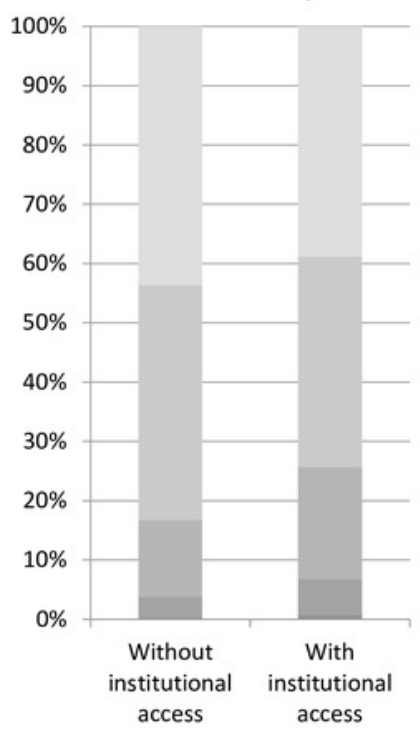


Figure 12

Relationship between "most desired" journals and Google Scholar h5 index of these journals $(n=235)$.

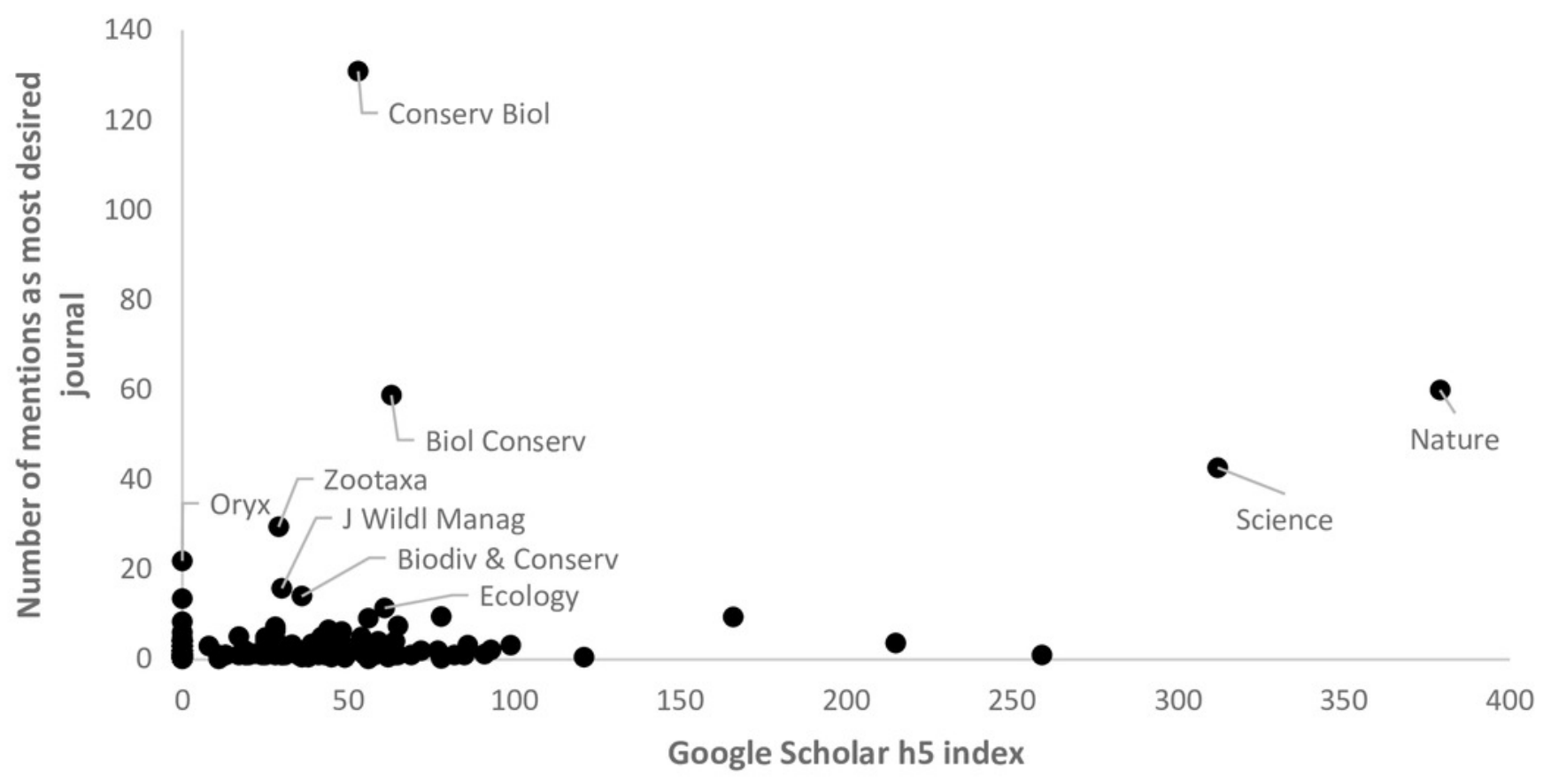

